\title{
Comparative Studies for Determining the Optical Band-gap Energy of the Novel Polycrystalline Thin Znga2s4 Films Sprayed at Different Film Thicknesses
}

\section{Ahmed Saeed Hassanien ( $\nabla$ a.s.hassanien@gmail.com )}

Benha University, Faculty of Engineering at Shoubra https://orcid.org/0000-0002-4605-9329

\section{Alaa A Akl}

Minia University Faculty of Science

I. M. El Radaf

National Research Center, Egypt

\section{Research Article}

Keywords: Polycrystalline thin films, Crystalline volume fraction, Optical absorption coefficient, Urbach energy, Tauc plot, Optical band-gap energy

Posted Date: March 18th, 2021

DOl: https://doi.org/10.21203/rs.3.rs-325892/v1

License: (c) (1) This work is licensed under a Creative Commons Attribution 4.0 International License.

Read Full License 


\title{
Full-Length Article
}

\section{Comparative studies for determining the optical band-gap energy of the Novel polycrystalline thin $\mathrm{ZnGa}_{2} \mathrm{~S}_{4}$ films sprayed at different film thicknesses}

\author{
Ahmed Saeed Hassanien ${ }^{a, b, *, 1}$, Alaa Ahmed Akl ${ }^{c, d}$, I.M. El Redaf ${ }^{e, f}$
}

\begin{abstract}
a) Mathematics and Eng. Physics Dept., Faculty of Engineering at Shoubra, 11629, Benha University, EGYPT
${ }^{b)}$ Physics Dept., Faculty of Science and Humanities (Afif Governorate) 11921, Shaqra University, KSA

c) Physics Dept., Faculty of Science, Minia University, El-Minia, 61519, Egypt

d) Physics Department, Faculty of Science and Humanities in Ad-Dawadmi, Shaqra University, 11911, Saudi Arabia

e) Physics Division, Electron Microscope and Thin Films Dept., National Research Centre, Dokki, Giza 12622, EGYPT

f) Materials Physics and Energy Laboratory, College of Sciences and Art at Ar-Rass, 51921, Qassim University, KSA
\end{abstract}

*E-mail of corresponding author: a.s.hassanien@gmail.com ; ahmed.hassanien@feng.bu.edu.eg

\section{ABSTRACT}

This article has dedicated to studying some structural features and optical characteristics of the Novel polycrystalline $\mathrm{ZnGa} \mathrm{S}_{4}$ (ZGS) thin films utilizing spray pyrolysis process at different thicknesses (293, 375, 452, and 517nm). The microstructural properties and crystal defects of these films have been studied in previous work. While in this work, the crystallinity degree and crystalline volume fraction have been studied using X-ray diffractograms. The stoichiometry of these ZnGa2S4 films has been checked using the energy dispersive $x$-ray analysis. The field-emission-scanning-electron microscope has been utilized to investigate the morphology of ZGS films' surfaces. Optical properties have been studied via transmittance and reflectance spectra in the range $300 \mathrm{~nm}-2500 \mathrm{~nm}$. Some important optical parameters such as absorption coefficient, skin depth, Urbach's energy, steepness parameters, and electron-phonon interactions have been extensively studied. The direct and indirect gap energy were determined by different four models and compared with Tauc's model. Optical data analysis revealed that; all studied properties are strongly dependent on the film thickness. The optical band gap values were slightly decreased from $3.7 \mathrm{eV}$ to $4.1 \mathrm{eV}$ with increment of the film thickness owing to improving the crystallization process. These obtained results confirm that these films are wide band gap semiconductors, which makes them recommended for use in many solar cell applications as a window layer.

Keywords: Polycrystalline thin films; Crystalline volume fraction; Optical absorption coefficient; Urbach energy; Tauc plot; Optical band-gap energy.

${ }^{1}$ Permanent address of A.S. Hassanien is:

Engeering Mathimatics and Physics Dept., Faculty of Engineering at Shoubra - Cairo, Benha University, EGYPT.

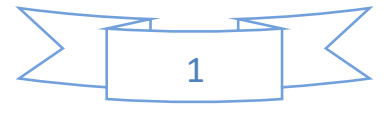




\section{Introduction}

In the last few decades, scientists, researchers and engineers have focused their efforts on studying manufactured novel materials that are used to convert photovoltaic energy into reliable electrical energy. So, there is an increased recall to use abundant, inexpensive, and environmentally friendly materials in thin-film solar cells. CuInGaSe 2 (CIGS) has been used as an absorbent in thin-film solar cells since it achieved the highest efficiency, which may reach about $20 \%$ [1-3]. The search for toxic elements, scarcity, and the need to reduce the cost of mass production are driving chalcogenide-based solar cells as one of the next generations of thin-film solar cells [3]. Recently, the chalcogenides (ChG) thin films have received much attention in the past years owing to their diverse and numerous applications in electronic devices and memory switching, as well as in the nonlinear optical devices [4-8]. These ChG materials are characterized by their low phonon energy and their transparency in visible and infrared regions [9-12]. Also be doped by some rare earth elements, like Pr, Er, Nd, ... etc. Moreover, these ChGglasses are highly optical nonlinear materials and hence can be used for the optical-switching devices, OS. These glasses are also sensitive to the absorption of electromagnetic radiation and show a variety of photoinduced effects because of illumination.

The ChG materials are varied and found in abundance in the earth and have distinct and unique characteristics such as good optical and electrical properties, as well as their cheap prices, ease of production, and chemical stability. Hence, and owing to these wonderful properties, they are very suitable for producing window layers and economical absorbers for the solar cells [13]. It is worth noting that, the fabrication of the window layers require a semiconducting material that has a wide band gap ( $3.5 \mathrm{eV}$ - $3.8 \mathrm{eV}$ ) and of higher transmittance [14]. These unique conditions have been exhibited in the metal oxides, such as $\mathrm{ZnO}, \mathrm{SnO}_{2}$, and $\mathrm{In}_{2} \mathrm{O}_{3}$, which have good efficiency to make as window layers of solar cells [15]. Moreover, the production of the absorbing layer of electromagnetic waves requires a semiconducting material that has a narrower energy gap $(1.0 \mathrm{eV}-1.5 \mathrm{eV})$, and a distinguished absorption of light of a wavelength arranged between $350 \mathrm{~nm}$ and $1000 \mathrm{~nm}$, i.e., more than $10^{4} \mathrm{~cm}^{-1}$ [16].

Thin $\mathrm{Cu}-\mathrm{ChG}$ films like either $\mathrm{Cu}-\mathrm{Zn}-\mathrm{Sn}-\mathrm{S}$, or $\mathrm{Cu}-\mathrm{Zn}-\mathrm{Sn}-\mathrm{Se}$, CZTS(Se) exhibited better efficiency in solar cells. The scientists and researchers deposited thin CZTS films utilizing the sputtering technique and then they have measured their p-type conductivity. The electronic transition was found to

be direct band gap about $1.45 \mathrm{eV}$, and their absorption coefficient was more than $10^{4} \mathrm{~cm}^{-1}$ in the visible region [17]. The CZTS compositions and their films can be crystallized as a bland-zinc crystalline structure similar to other semiconducting materials such as $\mathrm{Cu}-\mathrm{In}-\mathrm{Ga}-\mathrm{Se}, \mathrm{CIGSe}$, and Si. Generally,

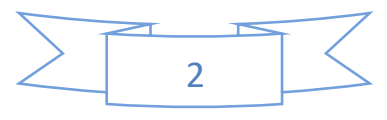


CZTS compositions can have two other forms; the first one is the stannite crystal structure, which has the same tetragonal coordination, but with unlike symmetry owing to the alternate situation of cations in the main crystal lattice. While the second is the wurtzite-derived crystal structure, which is a hexagonal close-packed array [18]. The three crystal structures have a formal $\mathrm{Cu}_{2} \mathrm{ZnSnS}_{4}$ stoichiometric, although the kesterite structure is the most often used in solar cells. The experimental procedures of manufacturing CZTS(Se) solar absorber layers could be classified into two different categories, they are: The vacuumbased techniques include flash evaporation, thermal evaporation, sputtering, and atomic layer deposition techniques. While the non-vacuum-based techniques (or the solution-based) processes include all chemical deposition processes, such as spray pyrolysis, sol-gel, electro-deposition, molecular precursors, and nano-crystal techniques [17-21].

The II-III $2-\mathrm{VI}_{4}$ compounds like $\mathrm{ZnIn}_{2} \mathrm{~S}_{4}, \mathrm{CdIn}_{2} \mathrm{~S}_{4}, \mathrm{ZnGa}_{2} \mathrm{~S}_{4}$, and $\mathrm{CdAl}_{2} \mathrm{~S}_{4}$ are also considered as significant $\mathrm{ChG}$ materials as they showed the n-type conductivity, higher transparency, and a wide gap ranged between $3.4 \mathrm{eV}$ and $3.8 \mathrm{eV}$ [19]. The importance of these $\mathrm{ChG}$ materials encourages the researchers to look for synthesizing of new compositions from this group, for the possibility of their using in solar cells as new optical windows [20]. The present work has focused on the novel thin $\mathrm{ZnGa} 2 \mathrm{~S} 4$ films owing to their non-toxic, low economical price, earth-abundant, and stability, along with their wide band gap and higher thermal stability.

The aim of the present work is to continue the previous study that presented a thorough study of the synthesis of the Novel nanocrystalline thin $\mathrm{ZnGa}_{2} \mathrm{~S}_{4}$ films of various thicknesses by an inexpensive spray pyrolysis technique. In addition, the authors have studied the effect of film thickness on the surface morphology, crystal structure, crystal defects, and microstructure properties of these novel films [21]. The X-ray diffractions, XRD, Field emission-scanning electron microscope, FESEM, and the energy dispersive X-ray spectroscopy, EDX techniques have been employed to inspect the structural characteristics of the $\mathrm{ZnGa}_{2} \mathrm{~S}_{4}$ thin films. Consequently, the authors of the current article will focus on studying the optical properties of these film samples. The optical characteristics of the films have been studied via studying the transmission, reflection, and absorption spectra and determining the parameters that describe the electronic transitions, such as: absorption coefficient, absorbance or optical density, the skin depth, band gap energy, Urbach energy, and valence band tails. Along with some important optical parameters of the $\mathrm{ZnGa}_{2} \mathrm{~S}_{4}$ thin films that related to the principal optical transitions in the UV, Vis, and IR regions have been investigated and discussed. Moreover, the optical band-gap 
energy values will be determined by various methods, such as Tauc's plots, the absorption-spectra fitting curves, ASF, Cody representations, and Davis-Mott model.

\section{Experimental details}

\section{1. $\mathrm{ZnGa}_{2} \mathrm{~S}_{4}$ film formation}

In this research work, an inexpensive spray pyrolysis method has employed to obtain the $\mathrm{ZnGa}_{2} \mathrm{~S}_{4}$ thin films. At first, we make substrate cleaning process to get the $\mathrm{ZnGa}_{2} \mathrm{~S}_{4}$ thin films of better quality. The used substrates are ordinary micro slides of soda lime glass of dimension $26 \times 76 \times 2 \mathrm{~mm}^{3}$ which have good optical characterizations. The cleaning process was carried out as follows; first, the glass sheets have been dipped in freshly equipped chromic acid, which has been heated up to $60^{\circ} \mathrm{C}$. The glass sheets have been removed from the acid and washed with a distilled water. Subsequently they were placed in the solution of an alkaline soap for at least ten minutes. Thereafter, they have been washing with running water, where the process of washing was repeated. Next, the substrates have been washed using doubledistilled water then using the ultrasonic waves. Finally, the glass sheets have been dried in a furnace of hot air. This removes any dust particles that may be sticking to a surface, ensuring maximum hygiene and making the film stickier to the substrate.

Chemicals in the powder form have been used to synthesize the $\mathrm{ZnGa}_{2} \mathrm{~S}_{4}$ solution. This solution was used to precipitate thin films using the spray pyrolysis process. These chemicals are $\left(\mathrm{GaCl}_{3}\right)$, $\left(\mathrm{Zn}\left(\mathrm{CH}_{3} \mathrm{COO}\right)_{2} \cdot 2 \mathrm{H}_{2} \mathrm{O}\right)$ and $\left(\mathrm{Na}_{2} \mathrm{~S}_{2} \mathrm{O}_{3} .5 \mathrm{H}_{2} \mathrm{O}\right)$ of molecular weights 281.26, 219.51 and 248.18, respectively. These chemical powders have high purity degrees (99.99\%) and were purchased from the company Sigma-Aldrich. These chemicals were utilized without any further purification.

The precursor solutions for fabricating the novel $\mathrm{ZnGa}_{2} \mathrm{~S}_{4}$ films were synthesized using: (i) 0.1 $\mathrm{M}$ from $\mathrm{Zn}\left(\mathrm{CH}_{3} \mathrm{COO}\right)_{2} \cdot 2 \mathrm{H}_{2} \mathrm{O}$, the zinc acetate dihydrate, (ii) $0.2 \mathrm{M}$ from $\mathrm{GaCl}_{3}$, gallium trichloride, which is used as a gallium source and (iii) $0.4 \mathrm{M}$ from $\mathrm{Na}_{2} \mathrm{~S}_{2} \mathrm{O}_{3}$, sodium thiosulfate, as a sulfur source. The $\mathrm{ZnGa}_{2} \mathrm{~S}_{4}$ solution was stirred well for one hour to produce a yellow solution. These molarity values were chosen to ensure that thin film having the stoichiometric ratio 1: 2: 4 were obtained. The $\mathrm{ZnGa}_{2} \mathrm{~S}_{4}$ solution was sprayed from a nozzle on the pre-cleaned glass substrates via the spray pyrolysis technique, where the substrate temperature was fixed at $300{ }^{\circ} \mathrm{C}$, the rate of flow was adjusted at $10 \mathrm{ml} / \mathrm{min}$, and the airflow pressure from the compressor was fixed invariant at 3 bar. While the distance between the spray nozzle and the substrate was fixed at $30 \mathrm{~cm}$, for all films. Furthermore, the deposition time during the spray process was 5, 10, 15, and 20 min to get thin films having these thicknesses: $293 \mathrm{~nm}, 375 \mathrm{~nm}, 452$ $\mathrm{nm}, 517 \mathrm{~nm}$, respectively, as measured by the alpha step D-500 stylus profilometer. It is worthy to

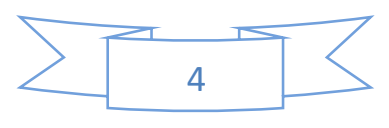


mention that the thickness of each film was measured multiple times, and mean values were taken into account. For more specifics on the used spray pyrolysis method and the experimental procedures that have been exercised during the preparation of film samples, refer to the authors' previous work [22-25].

\subsection{Materials characterization}

The polycrystalline nature of $\mathrm{ZnGa}_{2} \mathrm{~S}_{4}$ thin films was examined using a Philips-X'Pert X-ray diffractometer, with $C u K_{\alpha}$ radiation. The X-ray diffractograms were published elsewhere [21]. The crystallographic studies showed that the samples the tetragonal crystal nanostructure of the lattice constants equal $a=0.5272 \mathrm{~nm}$ and $c=1.0451 \mathrm{~nm}$ that consistent with the following XRD Cards: JCPDS 89-4207, 80-1707, and 40-1462. Moreover, the average crystallite size of films increased from $14 \mathrm{~nm}$ to $40 \mathrm{~nm}$ as the thickness of the film increased [21]. The compositional element percentages and the surface morphological features of the $\mathrm{ZnGa}_{2} \mathrm{~S}_{4}$ thin films were characterized via using the Quanta-FeG-250 USA field-emission-scanning-electron microscope, FE-SEM. The energy-dispersive X-ray spectroscopy technique, $E D A X$ was also employed to investigate the elemental compositions and the finding confirmed that all thin-films have a good stoichiometry, along with in a good match with the theoretical computations. For more details about these EDAX characteristics and FE-SEM micrographs, anyone can refer to the previous work [21]. Optical properties of the $\mathrm{ZnGa}_{2} \mathrm{~S}_{4}$ films were carried out via measuring the reflectance, $R$ and transmittance, $T$ of films in the spectral range $400 \mathrm{~nm}-2500 \mathrm{~nm}$. A double beam UV-Vis-NIR-Shimadzu spectrophotometer of the model UV-310-PC was used to record the $R$ - and $T$ spectra of the film samples. All optical measurements are performed at room temperature.

\section{Results and discussions}

\subsection{Sample identification and structural studies}

\subsubsection{FE-SEM and EDS investigations}

Optical microscopes are effective tools used to specify the morphology, microscopic structural imperfections, and macro- surface defects that may manifest in the crystalline films, especially the optically transparent microscopes. Where the electron beam interacts with the atoms of the film sample, to produce various signals. These signals provide good information about the morphology, topography, and compositional elements of the surface. The electron beam is generally scanned using raster scanning and the location of the beam is combined with the signal to produce an image [21]. By scanning the

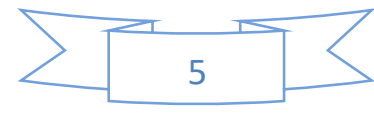


sample and collecting the secondary emitted electrons with a special detector, an image showing the surface morphology is created.

The morphological features of $\mathrm{ZnGa}_{2} \mathrm{~S}_{4}$ film surface have been scanned by the field-emissionscanning-electron microscope, FE-SEM of the type Quanta-FeG-250 USA. Figures (1-a) and (1-b) depict the obtained FE-SEM micrographs of nano-dimensions ZnGa2S4 films for the smallest thickness (293 $\mathrm{nm})$ and largest thickness $(517 \mathrm{~nm})$ samples, respectively, as typical samples of $\mathrm{ZnGa}_{2} \mathrm{~S}_{4}$ films. These FE-SEM micrographs show that the polycrystalline $\mathrm{ZnGa}_{2} \mathrm{~S}_{4}$ thin films have a good surface shape and that the particle sizes are almost homogeneous and uniform. These FE-SEM-micrographs also illustrate that the particle size of the film sample is almost increasing as the film thickness increases. This affirms the improvement of the crystallization of film and crystallinity degree of $\mathrm{ZnGa} 2 \mathrm{~S} 4$ film samples. These results are also in good matching with those obtained from the study of the X-ray diffraction.

On the other hand, the apparatus of FE-SEM has been equipped with interface equipment for the energy-dispersive x-ray spectroscopy investigations, EDS to check and analyze the percentage of the compositional elements of the studied thin films. The EDS spectra have been shown in Fig. (1-c) and Fig. (1-d) for these two films (of thicknesses $293 \mathrm{~nm}$ and the thickness $517 \mathrm{~nm}$, respectively), as representative film samples. The elemental percentages of the present thin $\mathrm{ZnGa}_{2} \mathrm{~S}_{4}$ film samples have been recorded in Table 1. The analysis of the EDS data and their chart spectra of the polycrystalline $\mathrm{ZnGa} 2 \mathrm{~S} 4$ thin films confirmed that all synthesized films are consisting of $\mathrm{Zn}, \mathrm{Ga}$, and S elements, only, and no others detected. It is worthy to mention that the atomic fractional percentages of the three constituent elements ( $\mathrm{Zn}, \mathrm{Ga}$, and $\mathrm{S}$ ) are almost stoichiometry, where their percentages were close to the ratio (1:2:4) for all films. Furthermore, it is observed that the percentage of the S-element is slightly increasing with the increment of the film thickness. This increase is occurring on the account of the $\mathrm{Si}$ percentage.

The thicker the film, the greater the distance traveled by the incident beam of electrons through the film compared to thinner films. Therefore, the higher the thickness of the film, the more accurate the percentages of the thin-film elements obtained for the film itself. At the same time as the thickness of the sample increases, it is found that the silicon percentage is decreasing. On the other hand, when excluding the percentage of Si originated from the glass substrate used, it turns out that the percentages of the three elements are almost invariant unaffected as the film thickness increases (maybe varied very slightly). This is because the solution used to prepare all samples has not changed, but what has changed is the deposition time that increases the film thickness.

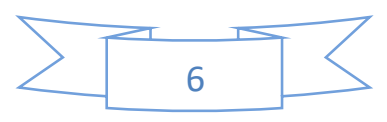




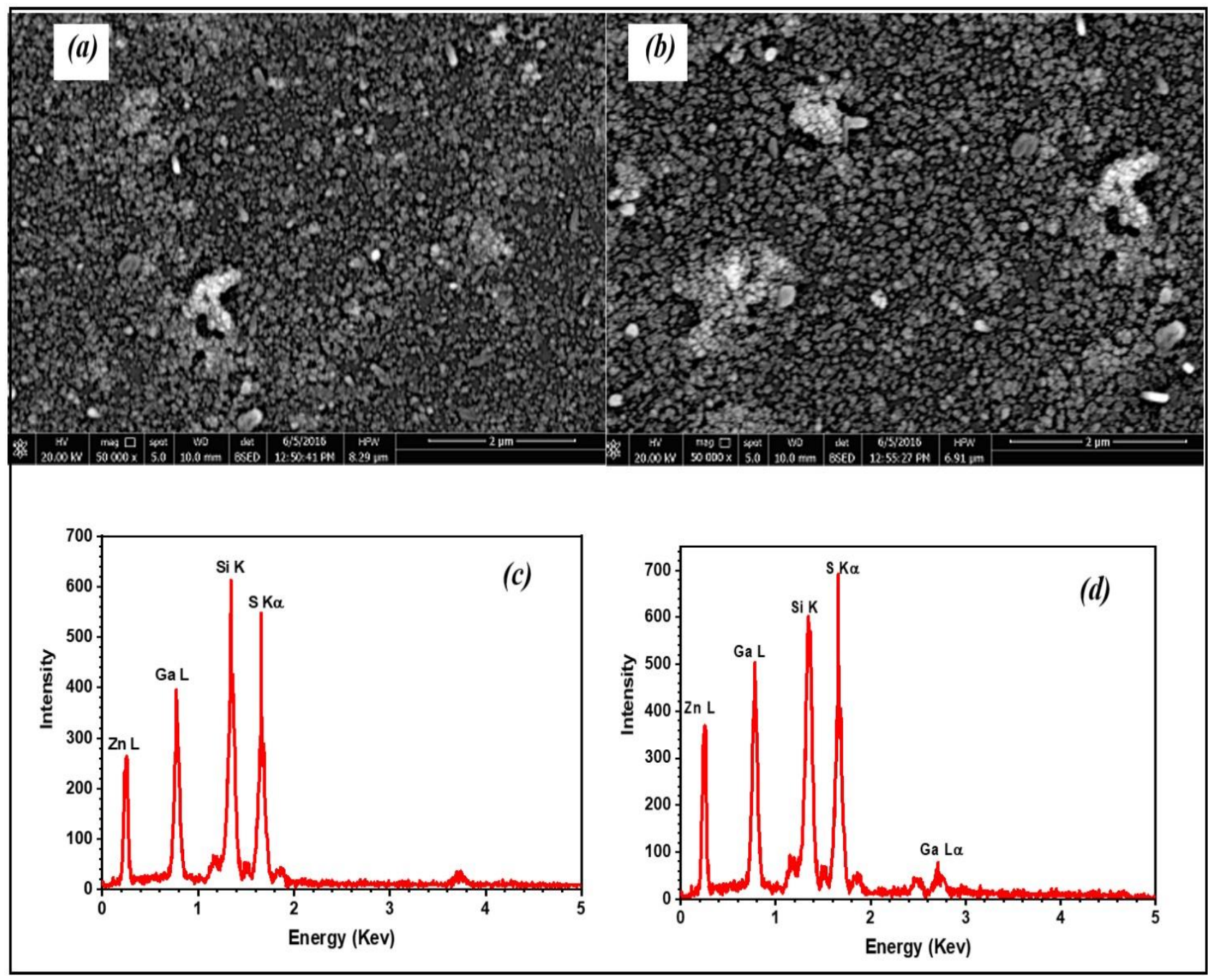

Fig. (1): FE-SEM micrographs ( $a$ and $b$ ) and EDS-spectra ( $c$ and $d$ ) of the present thinner and thicker film samples (of thicknesses $293 \mathrm{~nm}$ and $517 \mathrm{~nm}$ ), as typical samples of the ZnGa2 $\mathrm{S}_{4}$ thin films.

Table 1: The FE-SEM compositional element percentages of the polycrystalline ZnGa2S4 films.

\begin{tabular}{|c|c|c|c|c|c|c|c|}
\hline \multirow{2}{*}{$\begin{array}{c}\text { Thickness } \\
\text { of film } \\
\text { (nm) }\end{array}$} & \multicolumn{4}{|c|}{$\begin{array}{c}\text { Elements percentage included the Si of } \\
\text { glass substrates (at. \%) }\end{array}$} & \multicolumn{3}{|c|}{$\begin{array}{l}\text { Percentage of elements without that } \\
\text { of Si (at. \%) }\end{array}$} \\
\hline & $\mathrm{Zn}(\%)$ & Ga (\%) & $S(\%)$ & $\mathrm{Si}(\%)$ & $\mathrm{Zn}(\%)$ & Ga (\%) & $S(\%)$ \\
\hline 293 & 8.192 & 17.231 & 34.423 & 40.154 & 13.686 & 28.796 & 57.518 \\
\hline 375 & 8.530 & 17.954 & 35.281 & 38.235 & 13.683 & 28.797 & 57.520 \\
\hline 452 & 8.739 & 18.378 & 35.925 & 36.958 & 13.687 & 28.796 & 57.517 \\
\hline 517 & 9.381 & 19.122 & 36.311 & 35.186 & 13.684 & 28.801 & 57.515 \\
\hline
\end{tabular}




\subsubsection{Crystal structural studies}

$\mathrm{X}$-ray diffractograms, XRD of the current novel prepared thin $\mathrm{ZnGa}_{2} \mathrm{~S}_{4}$ films with different thicknesses have depicted that all films have the same polycrystalline nature, as shown in Fig. (2). The diffraction patterns are almost similar but with different intensities of the diffraction lines, as well as the

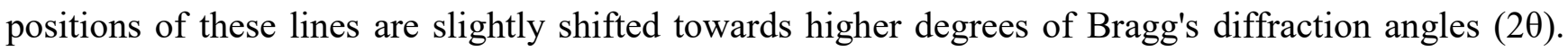
Moreover, the obtained diffraction lines are detected at the following diffraction angles $29.09^{\circ}, 31.61^{\circ}$, $36.98^{\circ}, 54.14^{\circ}$ and $65.15^{\circ}$ for the first film of thickness $293 \mathrm{~nm}$. These angles are in accordance with the following crystals' diffraction planes: (112), (103), (202), (310) and (206), respectively, as depicted in Fig. (2).
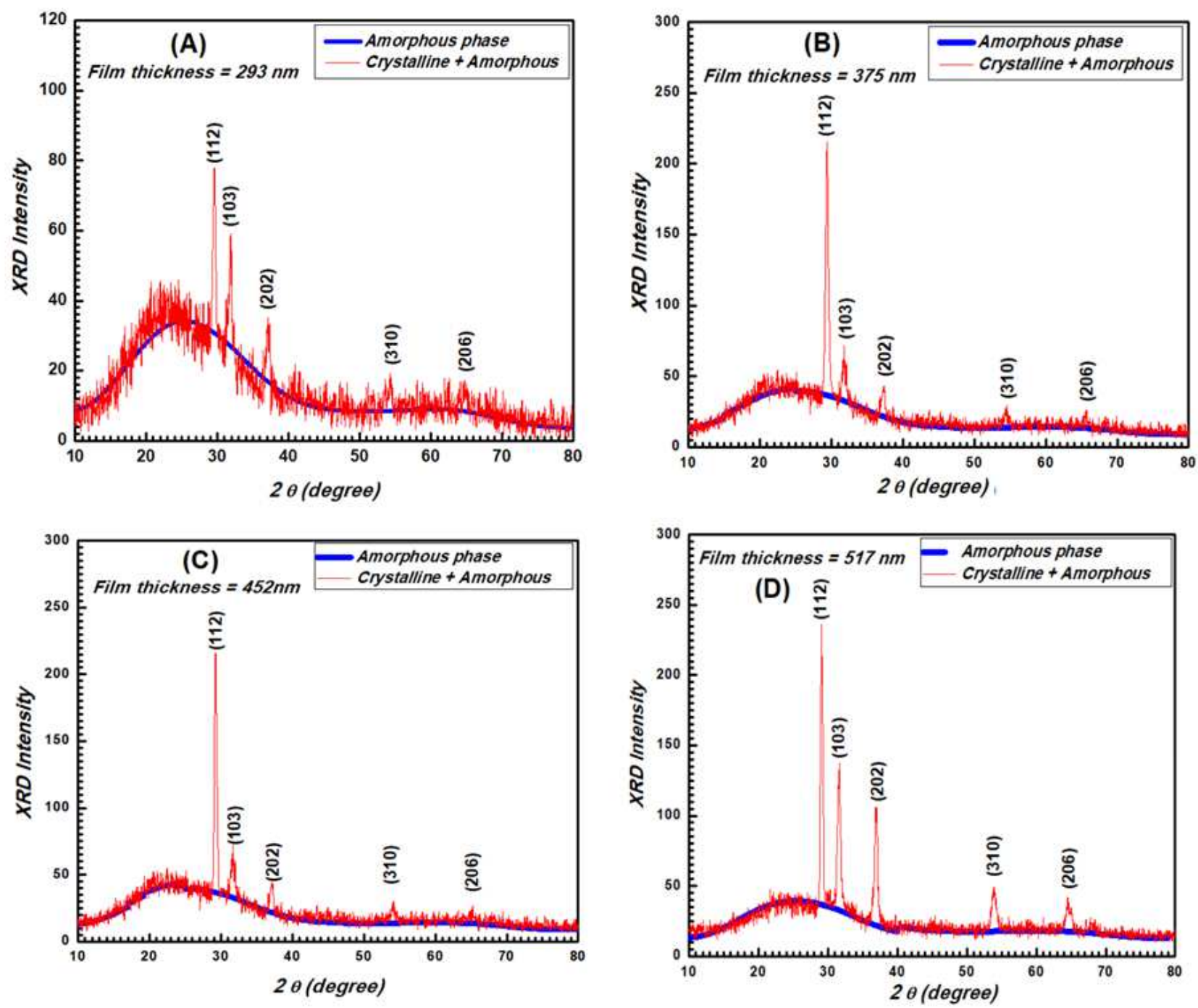

Fig. (2): X-ray diffraction pattern of the $\mathrm{ZnGa} \mathrm{a}_{2} \mathrm{~S}_{4}$ thin films of different thickness; The Red line represents the experimental curve (it is a mixture of the amorphous and crystalline phases), while Blue line is the amorphous phase. 
Further, these diffraction lines are also found to have strong intensity, which confirm that the film samples are well crystallized. These detected diffraction peaks are in good consistency with the following XRD carts: JCPDS card No. 40-1462, JCPDS card No. 80-1707 and JCPDS card No. 89-4207. It is worthy to mention that there are no other diffraction peaks except these observed five peaks, which confirm that the formed phase is the $\mathrm{ZnGa}_{2} \mathrm{~S}_{4}$ tetragonal polycrystalline phase. The details and explanations about the crystallography and crystal microstructure of these films were published elsewhere [21].

\subsubsection{Evaluation of the degree of crystallinity}

The physical, mechanical, and morphological properties of thin films depend on the degree of crystallinity and the direction of the preferred orientation growth during the preparation of materials and the deposition of film samples. Usually, these two factors have changed according to the used preparation route and the followed preparative parameters (such as the temperature of the substrate, the rate of the deposition, time of deposition, and the solution molarity). This is because of the growing crystallites of the films are exposed to thermal and kinetic energy during the deposition process. This increases the microscopic stress, lattice strains, and internal pressures that prevent the molecules from naturally arranging to form a certain crystal structure or to stacking in the form of crystals. This means that the degree of crystallinity of the thin films depends primarily on the preparation properties of those materials. Therefore, thin films are usually a mixture of crystalline and amorphous phases.

The XRD-charts of $\mathrm{ZnGa}_{2} \mathrm{~S}_{4}$ thin film shows that the crystallization process of films improves with increasing film thickness, where the diffraction Bragg's peaks become sharper and more intense with respect to the diffraction line of the crystalline phase of the largest thickness. The XRD-data can be employed to compute the crystallinity degree of the partially crystalline or polycrystalline films [26-30]. For the currently studied $\mathrm{ZnGa}_{2} \mathrm{~S}_{4}$ thin films, this procedure succeeded in integrating all diffraction peaks corresponding to the observed lines: (112), (103), (202), (310) and (206), where the intensity of the Xray diffraction lines is as depicted in Fig. (2). Subsequently, by summing these intensities into one intensity that represents the integration of the crystallized part. For the subsequent analysis, we adopted a two-phase concept typically applied to thin films in which the amorphous contribution to the spectrum, which occurs as a broad diffraction band has been approximated by the background curve separating the amorphous part from the crystalline portion. Then the degree of crystallinity of each sample was obtained as a ratio between the area under the crystalline peaks and the total area under the diffraction curve.

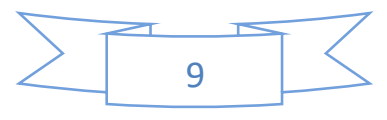


In this work, a typical fitting procedure was used to separate the crystalline peaks from the amorphous halo of the $\mathrm{ZnGa}_{2} \mathrm{~S}_{4}$ thin films of different thicknesses, as shown in Fig. (2). The crystal fraction was detached from the non-crystalline one using a computer program (EVA program) using the Hermans-Weidinger method [31]. Subsequently the degree of crystallinity, $\boldsymbol{X}_{\boldsymbol{C r y s t}}$ of each sample has been determined from the ratio between the area under the crystalline peaks, $\boldsymbol{A}_{\boldsymbol{C} \text { ryst }}$ and the whole area under the $\boldsymbol{X R D}$ curve, $\left(\boldsymbol{A}_{\text {Cryst }}+\boldsymbol{A}_{\text {Amorph }}\right)$ according to a simple formula:

$$
X_{\text {Cryst }}=\frac{A_{\text {Cryst }}}{\left(A_{\text {Cryst }}+A_{\text {Amorph }}\right)} \times 100
$$

It is clear from the tabulated results of Table 2 that the degree of crystallinity and the total area under the curves increase gradually with increasing the film thickness. This is evidence of an improvement in crystallinity of films and an increase in x-ray scattering. This in turn leads to a decrease in the amorphous ratio of the $\mathrm{ZnGa}_{2} \mathrm{~S}_{4}$ thin films. The crystalline percentage, $\boldsymbol{X}_{\boldsymbol{C r y s}}$ of thin $\mathrm{ZnGa}_{2} \mathrm{~S}_{4}$ films increases with the increment of the thickness of films from 9.204 to 16.921. This means that an increment in crystallinity of $\mathrm{ZnGa}_{2} \mathrm{~S}_{4}$ films has been observed for all samples of different thicknesses due to improvement in the crystallization. Consequently, it can be concluded that the film thickness increasing has a pronounced effect on the degree of crystallinity of $\mathrm{ZnGa}_{2} \mathrm{~S}_{4}$ thin films [32].

\subsubsection{Crystalline volume fraction}

The determination of the crystalline volume fraction, $\boldsymbol{V}_{\text {cryst }}$ of a substance can simply be considered as a quantitative phase analysis of two-phase materials (crystalline and amorphous phases). To work on such a hypothesis, a common XRD-based procedure as hypothesized by B.D. Cullity (1978) $[33,34]$. Thereby, to determine the volume fraction of the crystalline phase of partially crystalline materials from the structural measurements using XRD and by comparing the integrated intensities of the peaks derived from the amorphous and crystalline phases according to Huang's proposal [35]. In this case, the volume fraction of crystalline phase, $\boldsymbol{V}_{\text {Cryst }}$ can be estimated from the following Eq. [35]:

$V_{\text {Cryst }}=\frac{I_{\text {Cryst }}}{\left(I_{\text {Cryst }}+\alpha I_{A m}\right)}$

Where $\boldsymbol{I}_{\boldsymbol{C} r y s t}$ and $\boldsymbol{I}_{\boldsymbol{A} \boldsymbol{m}}$ are the integral intensities of the diffraction lines from the crystalline and amorphous phases, respectively. However, the parameter $(\alpha)$ is unknown, and it is called the Huang parameter. Indeed, for $\mathrm{Fe}_{73.5} \mathrm{Cu}_{1} \mathrm{Nb}_{3} \mathrm{Si}_{13.5} \mathrm{~B}$ alloy, $\alpha=1.05$ [36], and for $\mathrm{Al}_{88} \mathrm{Ni}_{4} \mathrm{Sm}_{8}, \alpha=0.37$ [37]. To determine the value of this $\alpha$-parameter, a series of diffraction patterns were measured which could be different for different systems. When subtracting the background of the diffraction pattern, the diffractograms could 
be decomposed into two components owing to the amorphous and crystalline phases and subsequently the integrated reflection intensities from each phase could be estimated.

Table 2: Analysis of X-ray diffraction data, degree of crystallinity, crystalline volume fraction and some optical factors of the Novel thin $\mathrm{ZnGa}_{2} \mathrm{~S}_{4}$ films with various thicknesses.

\begin{tabular}{|c|c|c|c|c|}
\hline \multirow{2}{*}{ Inferred parameters } & \multicolumn{4}{|c|}{ Film thickness (nm) } \\
\hline & 293 & 375 & 452 & 517 \\
\hline Area of amorphous; $A_{A m}$ & 1388.061 & 1408.047 & 1416.278 & 1528.428 \\
\hline Total Area; $A_{T}=\left(A_{C r y s t}+A_{A m}\right)$ & 1528.647 & 1614.848 & 1649.756 & 1839.811 \\
\hline Area of crystalline; Acryst $_{\text {Cry }}$ & 140.594 & 206.813 & 233.478 & 311.378 \\
\hline Degree of crystallinity; $X_{C r y s t} \%$ & 9.204 & 12.813 & 14.154 & 16.921 \\
\hline Amorphous ratio; $A_{A m} \%$ & 90.803 & 87.192 & 85.853 & 83.081 \\
\hline Intensity of crystalline \& amorphous; I Iotal & 70 & 219 & 221 & 241 \\
\hline Intensity of amorphous; $I_{A m}$ & 36.503 & 35.439 & 33.148 & 30.267 \\
\hline Intensity of crystalline phase; $I_{\text {Cryst }}$ & 33.503 & 183.561 & 187.848 & 210.728 \\
\hline Corrected amorphous phase intensity; $\alpha I_{A m}$ & 33.001 & 32.052 & 29.978 & 27.367 \\
\hline Crystalline phase; $C_{1}$ & 0.478 & 0.827 & 0.849 & 0.868 \\
\hline$C_{2}=I_{\text {Cryst }} /\left(I_{\text {Cryst }}+I_{A m}\right)$ & 0.311 & 0.722 & 0.741 & 0.779 \\
\hline Huang parameter; $\alpha$ & 0.904 & 0.904 & 0.904 & 0.904 \\
\hline Crystalline volume fraction; $V_{\text {Cryst }}$ & 0.325 & 0.851 & 0.862 & 0.885 \\
\hline Urbach energy, $E_{U}(e V)$ & 0.431 & 0.531 & 0.617 & 0.699 \\
\hline Absorption coefficient; $\alpha_{o} \times 10^{4}\left(\mathrm{~cm}^{-1}\right)$ & 2.664 & 3.242 & 3.681 & 3.378 \\
\hline Steepness parameter $(\sigma) \times 10^{3}$ & 60.051 & 48.704 & 41.927 & 37.005 \\
\hline The resistivity, $\rho_{o p t}(\Omega / m)$ & 12.509 & 19.758 & 45.658 & 94.338 \\
\hline The optical conductivity, $\sigma_{o p} \times 10^{-2}\left(\mathrm{~s}^{-1}\right)$ & 7.989 & 5.059 & 2.189 & 1.063 \\
\hline Electron -phonon interaction $\left(E_{e-p h}\right)$ & 11.103 & 13.689 & 15.902 & 18.021 \\
\hline $\begin{array}{l}\text { The wavelength of absorption edge } \\
\text { (direct transition) }(\lambda g),(\mathrm{nm}) \text { by ASF method }\end{array}$ & 302 & 307 & 323 & 330 \\
\hline $\begin{array}{l}\text { The wavelength of absorption edge } \\
\text { (indirect transition) }(\lambda g),(\mathrm{nm}) \text { by } A S F \text { method }\end{array}$ & 345 & 360 & 370 & 385 \\
\hline
\end{tabular}

Fig. (3) illustrates the dependence of the integrated intensity ratios of the real $\left(\boldsymbol{C}_{\boldsymbol{I}}\right)$ concentration of the crystalline phase in the sample $\boldsymbol{I}_{\boldsymbol{A} \boldsymbol{m}}$ and $\boldsymbol{I}_{\text {Cryst }}$ are integral intensities of the amorphous and crystalline phase, respectively, derived from the experimental data, and $\left(\boldsymbol{C}_{\boldsymbol{l}}\right)$ is the true concentration of the crystalline phase $[38,39]$. To find integrated intensities, the diffractions obtained in this way by Gaussians 
were approximated with the least squares fit. In this work the graphical relationship between $\boldsymbol{I}_{\text {cryst }}$ and $\left(\boldsymbol{I}_{\text {Cryst }}+\boldsymbol{I}_{\boldsymbol{A} \boldsymbol{m}}\right)$ was plotted versus the crystalline phase $\left(\boldsymbol{C}_{\boldsymbol{l}}\right)$ as a linear relationship and the slope was calculated so the value of $(\alpha)$ was equal to 0.9043 . It has been shown that the volumetric fractions of the crystal phase derived from different techniques can vary significantly [40].

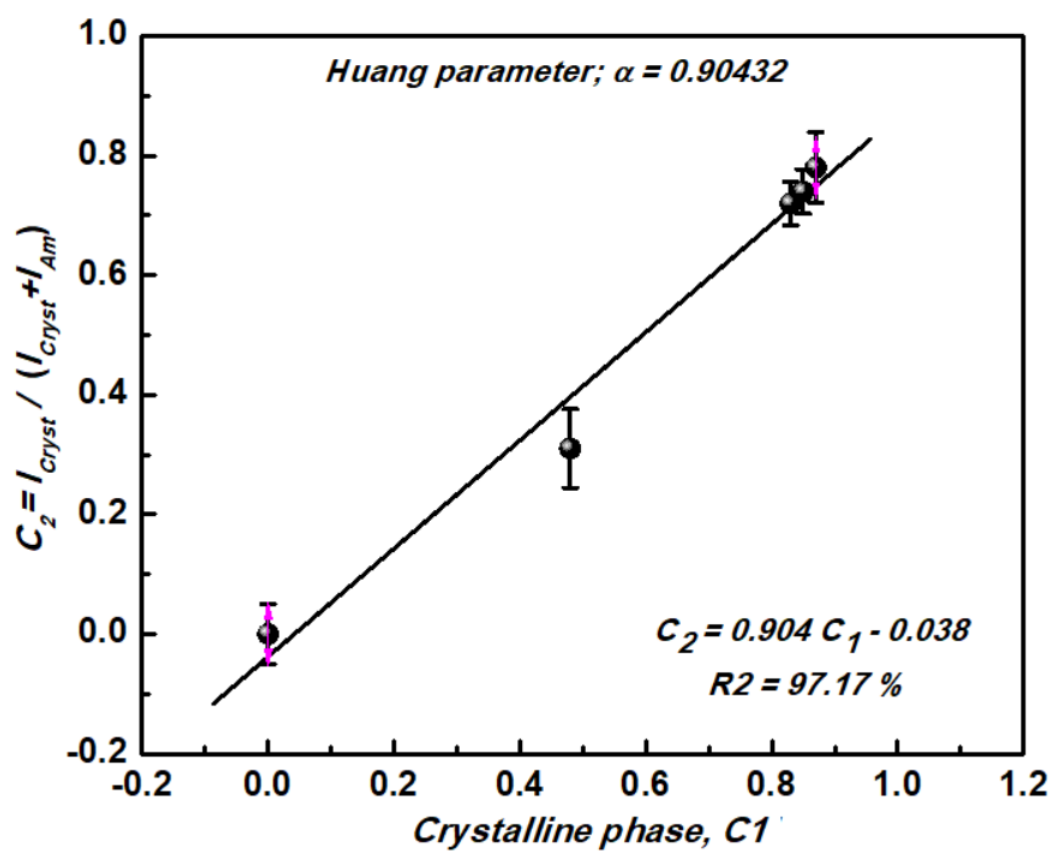

Fig. (3): Dependence of intensity's ratios for the integrated intensities on the true $C_{1}$ concentration of the crystalline phase, the slope of the straight line represents the $\alpha$-coefficient (Huang parameter).

The crystalline volume fraction, $\boldsymbol{V}_{\boldsymbol{C} \text { ryst }}$ of the investigated samples were calculated by the change of film thickness and recorded in Table 2. It is clear that, this fraction, $\boldsymbol{V}_{\boldsymbol{C r y s}}$, was found to be in the range from 0.325 to 0.885 for crystalline $\mathrm{ZnGa}_{2} \mathrm{~S}_{4}$ films as the increment of thickness from $293 \mathrm{~nm}$ to $517 \mathrm{~nm}$, respectively. It can be observed that the increase in the film thickness induces a change in the amorphouscrystalline transition, showing an increase in $\boldsymbol{V}_{\boldsymbol{C} \text { ryst }}$ for the investigated samples. As the film thickness increases, the growth of the repeated layers of ions increases, leading to the construction of a crystal agglomerations. Thus, complete grain growth does not occur, which reduces the formation of crystallite of $\mathrm{ZnGa}_{2} \mathrm{~S}_{4}$. This fact is related to a crystallization of the material for higher film thickness [41]. 


\subsection{Optical characteristics}

\subsubsection{Transmittance and reflectance spectra}

The optical parameters of the examined thin $\mathrm{ZnGa}_{2} \mathrm{~S}_{4}$ films have been determined from the transmission and reflection data. The spectral variation of the normal transmittance $T_{\exp }(\lambda)$ and reflectance $R_{\exp }(\lambda)$ due to the effect of the used substrate is given as follows [42,43]:

$$
\begin{aligned}
& T_{f}(\lambda)=\frac{T_{\exp } T_{\text {sub }}\left(1-R_{\exp } R_{\text {sub }}\right)}{T_{\text {sub }}^{2}-T_{\exp }^{2} R_{\text {sub }}^{2}} \\
& R_{f}(\lambda)=\frac{R_{\exp } T_{s u b}^{2}-T_{\exp }^{2} R_{\text {sub }}}{T_{\text {sub }}^{2}-T_{\exp }^{2} R_{s u b}^{2}}
\end{aligned}
$$

Where $\boldsymbol{T}_{\text {sub }}$ is the transmittance and $\boldsymbol{R}_{\text {sub }}$ is the reflectance of the glass substrate. Figs. (4-a) and (4-b) show the corrected optical transmittance $\boldsymbol{T}_{\boldsymbol{f}}(\lambda)$ and reflectance $\boldsymbol{R}_{\boldsymbol{f}}(\boldsymbol{\lambda})$ of the current $\mathrm{ZnGa}_{2} \mathrm{~S}_{4}$ thin films measured in the wavelength range from $300 \mathrm{~nm}$ to $2500 \mathrm{~nm}$. The transmittance and absorbance of thin films of various thicknesses increase without the presence of a shift in the absorbing edge, while the reflectance exhibits the opposite behavior with the change in the film thickness. These variations can be attributed to the crystallinity improvement of films and enhancing of the crystallization process and the film morphology, along with the minimizing of the crystal defects [23].
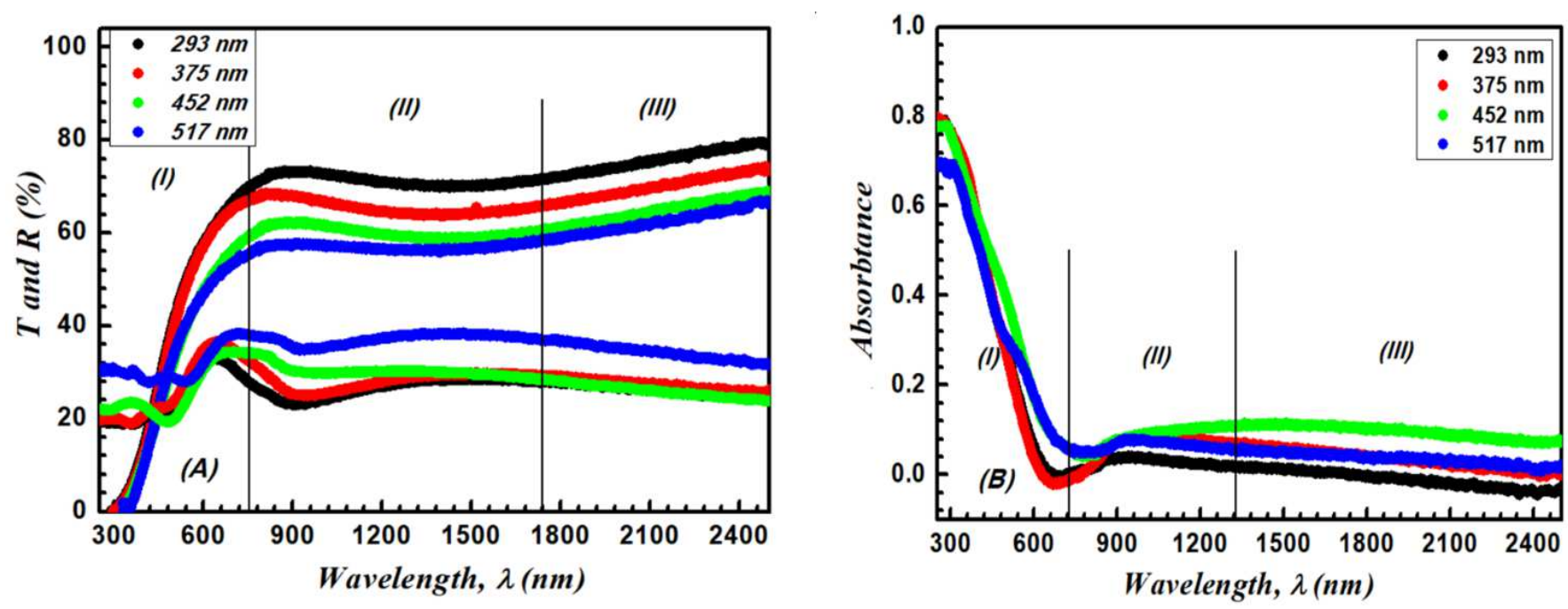

Fig. (4): The spectral variations of (a) transmittance and reflectance, and (b) absorbance as functions of the wavelength incident on thin $\mathrm{ZnGa}_{2} \mathrm{~S}_{4}$ films.

It can also be observed that the transmittance and absorption spectra of all thin films can be divided into three main special regions: (1) the strong absorption region, which extends to wavelengths

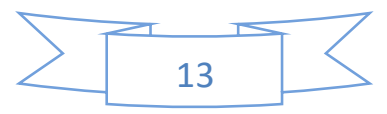


smaller than $750 \mathrm{~nm}$, (2) the transparent region, which is after the wavelength of $1750 \mathrm{~nm}$; (3) The absorption region between these two regions $(750 \mathrm{~nm}-1750 \mathrm{~nm})$. Also, the spectral distribution of both transmittance $\boldsymbol{T}(\lambda)$ is decreasing while that of the reflectance $\boldsymbol{R}(\lambda)$ is gradually increasing as increasing the film thickness. This is due to improving the film crystallinity and minimizing the crystal defects [23], which in turn leads to the increase in absorption of the $\mathrm{ZnGa}_{2} \mathrm{~S}_{4}$ thin films of different thicknesses. Moreover, the absorption edge remains unchanged with increasing film thickness while the summation of $\mathrm{T}$ and $\mathrm{R}$ is less than the unity after the absorption edge due to the scattering of light produced by the roughness of the surface of the studied films [43-46].

\subsubsection{Absorption coefficients}

The absorption coefficient of materials plays a substantial role in choosing a specified material to be used in the possible applications, especially semiconductor materials. Along with, the study of the absorption nature of this material supplies basic information about the forbidden optical band gap and the electronic transitions type of materials. Therefore, it was indispensable to study the absorption coefficient $(\alpha)$ of the thin $\mathrm{ZnGa}_{2} \mathrm{~S}_{4}$ films. The values of the absorption coefficient can be inferred through the spectra of both transmittance, $\boldsymbol{T}(\lambda)$, and reflectance, $\boldsymbol{R}(\lambda)$. This coefficient, $\alpha$, can be computed from this Eq. [47-49]:

$$
\alpha(\lambda)=\frac{1}{t} \operatorname{Ln}\left[\frac{(1-R)^{2}}{2 T}+\sqrt{\frac{(1-R)^{4}}{4 T^{2}}+R^{2}}\right]
$$

Where $\boldsymbol{T}, \boldsymbol{R}$ and $\boldsymbol{t}$ are the transmittance, reflectance, and the thickness of $\mathrm{ZnGa}_{2} \mathrm{~S}_{4}$ thin films in centimeters. High absorption coefficient values after the bandgap range are among the most important and critical characterizations of thin films. The extremely high $\alpha$-values, in the order of $10^{4} \mathrm{~cm}^{-1}$ and more than this, increase the importance of ternary compositions and their suitability in optoelectronic applications, which is the case for $\mathrm{ZnGa}_{2} \mathrm{~S}_{4}$ thin films. The variation of the absorption coefficient versus the incident wavelength at and near the absorption edge of the $\mathrm{ZnGa}_{2} \mathrm{~S}_{4}$ thin films is shown in Fig. (5-a) and Fig. (5-b). These figures depict that the absorption coefficient increases significantly to the highest value at about $300 \mathrm{~nm}$ wavelengths at the edge to reach values of approximately $2.5 \times 10^{4} \mathrm{~cm}^{-1}$. Subsequently its value suddenly decreases at a wavelength ranging from $500 \mathrm{~nm}$ to $600 \mathrm{~nm}$ and thereafter reaches an invariant value after a wavelength of more than $600 \mathrm{~nm}$, for all film samples. It is also clear that films of smaller thickness have higher absorption coefficient values in the visible region, but after $750 \mathrm{~nm}$, all films have almost the same absorption values. The published literature has shown that these results are well consistent with many similar semiconductor films [49-51]. 

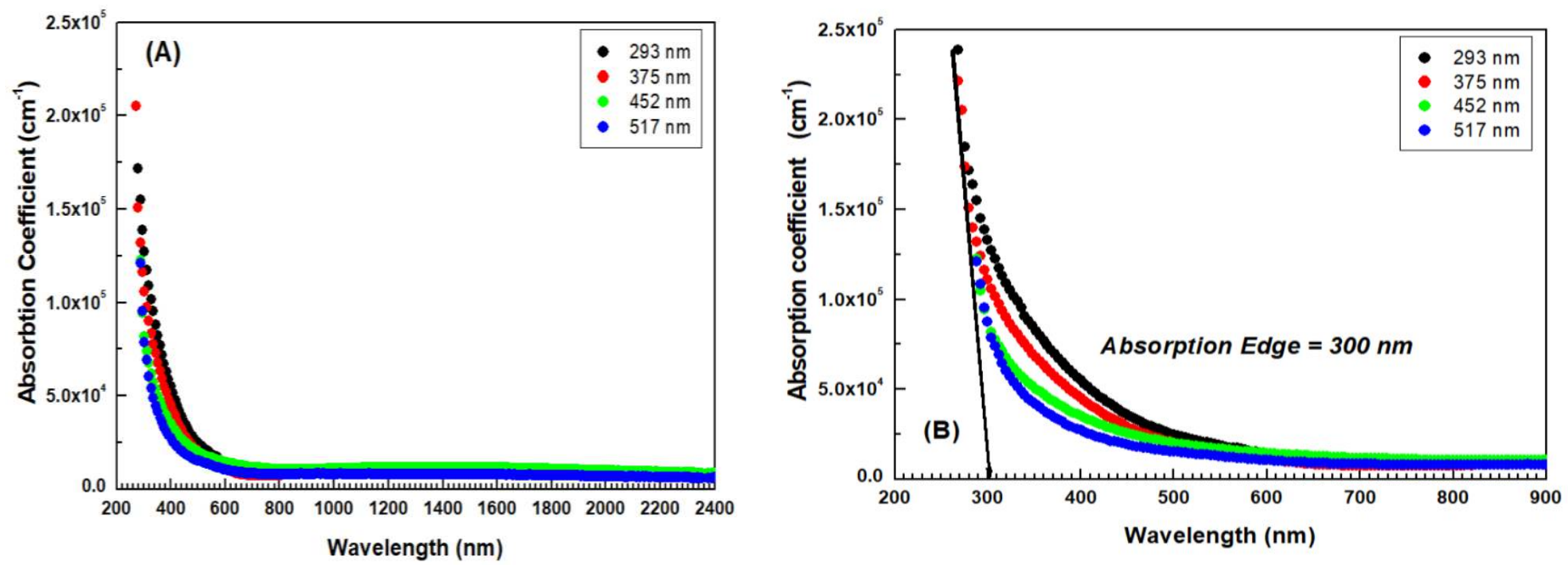

Fig. (5): The variation of the absorption coefficient versus the wavelength of thin ZnGa2S4 films (a) along the studied range and $(b)$ at the absorption edge.

\subsubsection{Skin effects and skin depth}

The absorption of electromagnetic waves in thin semiconductor films relies on many parameters, the most important of which are (1) the type of film material itself, (2) the thickness of the film, (3) the morphology of the film surface, and (4) the absorption index of the film material (k), as well as the optical conductivity of the film. When a ray of light passes through thin films, the photon intensity decreases dramatically for many reasons, like the density of the material, refractive index, morphology of the surface, and the film microstructure. When the optical intensity of the photon becomes (1/e) below the surface of the thin film, subsequently the thickness of the film that causes this is called skin depth $(\boldsymbol{\delta} \boldsymbol{d})$. This depth also depends on the photon frequency and the film's optical conductivity, which depends extremely on the width of the forbidden bandgap. So, the two parameters $(\boldsymbol{\alpha})$ and $(\boldsymbol{\delta} \boldsymbol{d})$ for any film could be linked by these forms [52-54]:

$$
\begin{aligned}
& \delta_{d}=\frac{1}{\alpha}=\frac{\lambda}{4 \pi k}=\sqrt{\frac{\rho_{o p t}}{\pi \cdot \mu_{o} \mu_{r . f}}} \\
& \delta_{d}=\sqrt{\frac{\lambda}{\pi \cdot c \cdot \mu_{o} \mu_{r} \sigma_{o p t}}}=\frac{1}{\sqrt{\pi \cdot c \cdot \mu_{o} \cdot \mu_{r} \cdot \sigma_{o p t}}} \cdot \sqrt{\lambda}
\end{aligned}
$$

Where $\rho_{\text {opt }}$ and $\boldsymbol{\sigma}_{\text {opt }}$ are the optical resistivity and conductivity, respectively of the thin $\mathrm{ZnGa}_{2} \mathrm{~S}_{4}$ film, $\boldsymbol{f}$ is the frequency. While $\boldsymbol{\mu}_{\boldsymbol{r}}$ and $\boldsymbol{\mu}_{\boldsymbol{o}}$ are the relative permeability which is usually considered to be the unity and the absolute permeability constant, respectively $\left(\boldsymbol{\mu}_{\boldsymbol{r}}=1\right.$ and $\left.\boldsymbol{\mu}_{\boldsymbol{o}}=4 \pi \times 10^{-7} \mathrm{H} / \mathrm{m}\right)$. Using the spectra of 
( $\alpha$ ) the depth, $\boldsymbol{\delta} \boldsymbol{d}$ can be computed for $\mathrm{ZnGa}_{2} \mathrm{~S}_{4}$ thin films. Figure (6-A) exhibits the variation of ( $\left.\boldsymbol{\delta} \boldsymbol{d}\right)$ versus the photon energy (hv) for the thin $\mathrm{ZnGa}_{2} \mathrm{~S}_{4}$ films of different thicknesses.
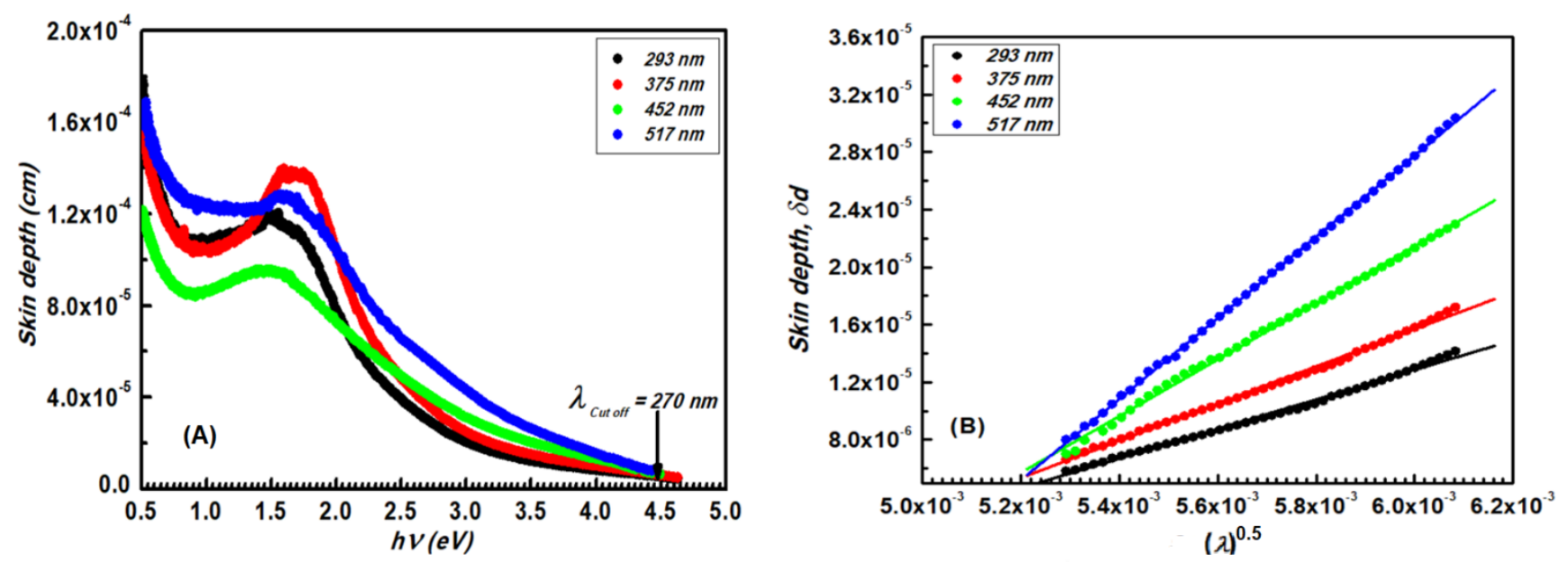

Fig. (6): Variation of the skin depth as a function of (a) the photon energy and (b) $\sqrt{\lambda}$, for ZnGa $\mathrm{Z}_{4}$ films of different thicknesses.

The figure illustrates that the spectral values of $\boldsymbol{\delta} \boldsymbol{d}$ decrease as the increment of the photon energy and the influence of absorption will be vanished at a certain point, which is the cut-off of the wavelength. It is observed also that at energy values larger than or equal to the optical gap energy, the $\boldsymbol{\delta} \boldsymbol{d}$-value decreases gradually till it reaches/approaches zero value. The energy value at which the depth $\boldsymbol{\delta} \boldsymbol{d}$ reaches the zero value is called the cut-off energy, $\boldsymbol{E}_{\text {cut-off }}$ and the corresponding wavelength is called the cut-off wavelength, $\lambda_{\text {cut-off. }}$ The $\boldsymbol{E}_{\text {cut-off }}$ value $=4.490 \mathrm{eV}$, and $\boldsymbol{\lambda}_{\text {cut-off }}=275 \mathrm{~nm}$, for the current thin $\mathrm{ZnGa}_{2} \mathrm{~S}_{4}$ films (See the figure). Hence, the absorption of the present films completely vanished at wavelengths less than $275 \mathrm{~nm}$, and the wave amplitude is decreasing after traveling a long distance, where $\boldsymbol{\delta}_{\boldsymbol{d}}$ depends on the transmittance, $\boldsymbol{T}$ ( $\lambda$ ) of films. Similar results have been obtained for some previous work on semiconductor films [55-59].

On the other hand, and according to Eq. (6), $\boldsymbol{\sigma}_{\text {opt }}$ of thin $\mathrm{ZnGa}_{2} \mathrm{~S}_{4}$ films can be deduced from ( $\left.\boldsymbol{\delta} \boldsymbol{d}\right)$ and $(\sqrt{\lambda})$. Fig. (7-b) illustrates the dependence of $\left(\boldsymbol{\delta}_{d}\right)$ on $(\sqrt{\lambda})$ of the thin $\mathrm{ZnGa}_{2} \mathrm{~S}_{4}$ films of different thicknesses. It can observe that the relationship between $(\boldsymbol{\delta} \boldsymbol{d})$ and $(\sqrt{\lambda})$ is a linear relationship for all thicknesses and almost increases with the thickness. The values of the optical conductivity, $\sigma_{\text {opt }}$ and the resistivity, $\boldsymbol{\rho}_{\text {opt }}$ at different film thicknesses of the $\mathrm{ZnGa}_{2} \mathrm{~S}_{4}$ were estimated from the straight-line's slope that was fitted, as illustrated in the Fig. (7-b) and subsequently recorded in Table 2. It can also observe here that the $\left(\sigma_{\text {opt }}\right)$-values decrease as the film thickness increases. This is owing to several reasons, like the activated thermal transfer of electrons from VB to $\mathrm{CB}$ in the semiconducting materials, and the charge

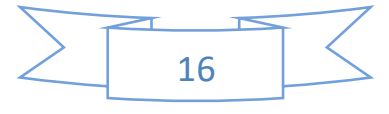


carriers short-range hopping at the grain boundaries, as well as the localized hopping of the charge carriers within the grains, too [59]. Additionally, the strong coupling between an electron and a phonon is formed by the vibrations of the ions of the crystal lattice at a limited temperature known as a polaron $[59,60]$.

\subsubsection{Urbach energy}

The absorption coefficients of the thin $\mathrm{ZnGa}_{2} \mathrm{~S}_{4}$ films are shown as the exponential rise, called the tail of Urbach which exists down the excitonic peaks. This tail, which has an exponential nature, appears in polycrystalline, partially crystalline, and non-crystalline materials, because of the existence of these localized states, which extended in the forbidden gap between $\boldsymbol{V B}$ and $\boldsymbol{C B}$ [61-63]. Where this band tail's energy can be estimated from the spectral variations of the logarithmic value of the coefficient of absorption ( $\ln \boldsymbol{\alpha}$ ) and the energy of the photon (hv) according to the Urbach's experimental Eq., which has the following form [47]:

$$
\alpha=\alpha_{o} \exp \left(\frac{h v}{E_{U}}\right)
$$

Where $\boldsymbol{\alpha}_{\boldsymbol{o}}$ is constant and $\boldsymbol{E}_{\boldsymbol{U}}$ refers to the energy of the band- tail width (Urbach energy). This energy, $\boldsymbol{E}_{\boldsymbol{U}}$ depends slightly on temperature and is often interpreted as the band-tail width owing to the localized states in the forbidden band gap and associated with the perturbation of the non-crystalline and low crystalline materials [ 47,64-66]. Taking the logarithmic value of the two sides of Eq. (8), thus, it could obtain an equation of a straight line:

$$
\operatorname{Ln} \alpha=\operatorname{Ln} \alpha_{o}+\frac{h v}{E_{U}}
$$

Consequently, the energy $\left(\boldsymbol{E}_{U}\right)$ can be evaluated from the reciprocal of the slope of the line when In $(\boldsymbol{\alpha})$ versus $(\boldsymbol{h v})$ is plotted. Fig. (7-a) depicts this representation, where it illustrates the low absorption range (Urbach energy) and high absorption range (Tauc regions). Moreover, Fig. (7-b) exhibits the straight part of the Urbach exponential region if $\boldsymbol{l n}(\boldsymbol{\alpha})$-values are represented versus $(\boldsymbol{h} \boldsymbol{v})$-values for the thin $\mathrm{ZnGa}_{2} \mathrm{~S}_{4}$ films of variable thicknesses, so that the slope $=\left(\boldsymbol{1} / \boldsymbol{E}_{\boldsymbol{U}}\right)$ and cut-crossed value from the ordinate gives $\boldsymbol{l n}\left(\boldsymbol{\alpha}_{\boldsymbol{o}}\right)$. The determined values of $\left(\boldsymbol{E}_{\boldsymbol{U}}\right)$ and $\left(\boldsymbol{\alpha}_{\boldsymbol{o}}\right)$ are recorded in Table 2. Apparently, the values of both $\left(\boldsymbol{E}_{U}\right)$ and $\boldsymbol{\alpha}_{\boldsymbol{o}}$ increase with the increment of the thickness of the films. This points out that a significant improvement in the crystallinity degree of the thin $\mathrm{ZnGa}_{2} \mathrm{~S}_{4}$ films. The literature of similar works shows that the obtained results have the same trend [66-68]. Further, these results have already been affirmed from XRD findings. 

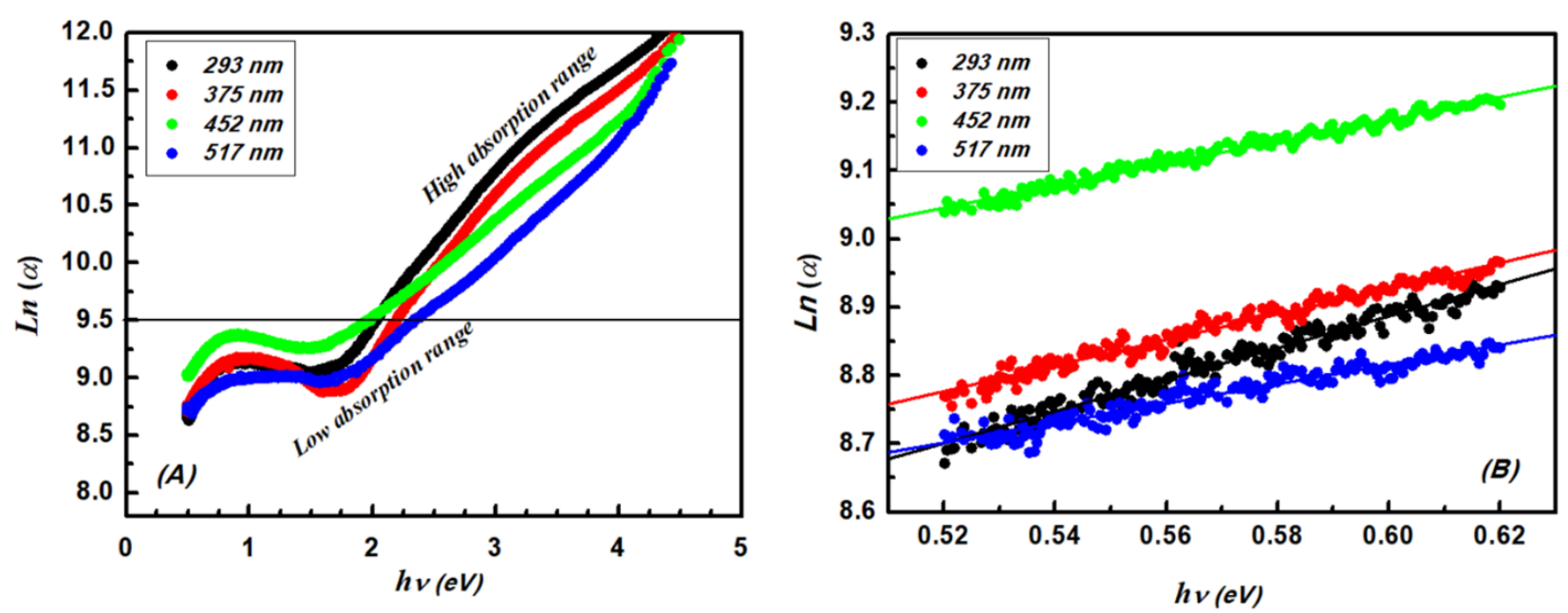

Fig. (7): Plotting of $\ln (\alpha)$ versus (hv) of the polycrystalline $\mathrm{ZnGa} 2 \mathrm{~S}_{4}$ thin films. (A) shows the low and high absorption range (Urbach and Tauc regions, respectively) and $(B)$ shows linear relationship.

According to Urbach assumption, there is another formula that correlates the two parameters $(\alpha)$ and $\left(\boldsymbol{E}_{g}\right)$ according to his suggestion [67-69]:

$\alpha=\beta \operatorname{Exp}\left[\frac{\sigma\left(h v-E_{o}\right)}{K_{B} T}\right]$

Where $\boldsymbol{\sigma}$ is a new optical constant called the steepness parameter, $\boldsymbol{\beta}$ is another pre-exponential parameter, $\boldsymbol{E}_{\boldsymbol{o}}$ is the energy of the electronic transitions, its value depends upon the electronic transition, where: For direct transitions: $\boldsymbol{E}_{\boldsymbol{o}}=\boldsymbol{E}_{g}$; While for the indirect transitions: $\boldsymbol{E}_{\boldsymbol{o}}=\boldsymbol{E}_{g} \pm \boldsymbol{E}_{\boldsymbol{p h}}$. Where the energy parameter, $\boldsymbol{E}_{\boldsymbol{p h}}$ represents the energy that bounds the phonon. Hence, $\boldsymbol{E}_{\boldsymbol{p} \boldsymbol{h}}=\boldsymbol{0}$ for the current study. Hence, if the direct transition case is considered, then $\boldsymbol{E}_{\boldsymbol{o}}=\boldsymbol{E}_{\boldsymbol{g}}$. Thus, it can substitute and reformulate Eq. (10) to get the following form:

$$
\begin{aligned}
& \operatorname{Ln} \alpha=\operatorname{Ln} \beta+\frac{\sigma h v}{K_{B} T}-\frac{\sigma E_{g}}{K_{B} T} \\
& \operatorname{Ln} \alpha=\left(\operatorname{Ln} \beta-\frac{\sigma E_{g}}{K_{B} T}\right)+\frac{\sigma h v}{K_{B} T}
\end{aligned}
$$

From Eqns. (9) and (12), it can conclude that:

$\operatorname{Ln} \alpha_{o}=\operatorname{Ln} \beta-\frac{\sigma E_{g}}{K_{B}}$

And

$\frac{h v}{E_{U}}=\frac{\sigma h v}{K_{B} T}$ 
Therefore, the estimation of the sharpness or steepness of the absorption edge, which is called the regression parameter $(\sigma)$, and is calculated as follows:

$\sigma=K_{B} \times \frac{T}{E_{U}}$

Where $\boldsymbol{K}_{\boldsymbol{B}}$ is the Boltzmann's constant, and $\mathrm{T}$ is the room temperature $(300 \mathrm{~K}), \mathrm{K}_{\boldsymbol{B}}=8.6173 \times 10^{-5} \mathrm{eV} / \mathrm{K}$. Hence, the steepness parameter, $\boldsymbol{\sigma}$ of the ternary compound $\mathrm{ZnGa}_{2} \mathrm{~S}_{4}$ thin films has been computed for all films of varying thicknesses and recorded in Table 2. It is clear that, the steepness parameter decreases with the increment of the film thickness, which is acceptable results due to the increased value of the Urbach band-tail energy. On the other hand, the strength of the interaction between the electron and the phonon $\left(\boldsymbol{E}_{\boldsymbol{e}-\boldsymbol{p} \boldsymbol{h}}\right)$ is linked with the parameters $(\boldsymbol{\sigma})$ by this simple form $[63,69]$ :

$E_{e-p h}=\frac{2}{3 \sigma}$

Consequently, the value of the strength of interactions $\left(\boldsymbol{E}_{\boldsymbol{e}-\boldsymbol{p} \boldsymbol{h}}\right)$ could be determined for the present films and subsequently recorded in Table 2 . It can be seen that there is a gradual increase in the steepness parameter values with the values of electron-phonon interaction decrease as the increase in the film thickness. The decrease in the strength of the interaction between the electron and phonons can be attributed to the increase in the vibrational motion of atoms, unit cells, and crystal lattices, along with the improvement in the degree of crystallinity. It is worthy to note that the resultant greatest values of the atomic vibrational motion do not match with the free-electron frequencies of the ternary $\mathrm{ZnGa}_{2} \mathrm{~S}_{4}$ thin films. Thus, there is no coupling between the free-electrons' frequency and that of the phonons. [70].

\subsubsection{Optical band-gap energy}

As a result of the extreme importance of the optical band gap of the semiconducting materials and the energy value of this gap, there were many attempts to study this optical band gap and deducing the amount of energy required for the electronic transition from the level of the valence band to that of the conduction band. Thus, several models are used to evaluate the energy of the band gap, such as the absorption spectra fitting (ASF) procedure, Tauc's plots, Cody representations, and Davis-Mott model. These assumptions and models are based on the value of the absorption coefficient, $\boldsymbol{\alpha}$ which appears near the edge of the band in semiconductors as an exponential function of the photon energy according to the following empirical relationship [47]:

$\alpha h v=B\left(h v-E_{g a p}\right)^{y}$ 
Where $\boldsymbol{B}$ is a parameter associated with the structural order of the semiconductors, $\boldsymbol{E}_{\boldsymbol{g a p}}$ is the band-gap energy of the studied material, $\boldsymbol{h} \boldsymbol{v}$ is the energy of the incident electromagnetic waves and the exponent $(y)$ is a parameter determines the nature of the electronic transitions. Since the value of $(y)$ is what determines the type of transition; if it is allowed or forbidden; direct or indirect. If $y$ is equal to $1 / 2$ then the transition is allowed direct, but if it is equal to 2 then the transition is allowed indirect transition $[47,57,69]$.

In this study, the authors will infer the optical bandgap energy values using different models, and subsequently compare these results to judge which models give the best and most accurate result.

\subsubsection{Absorption spectrum fitting (ASF) procedure}

The absorption spectrum fitting (ASF) procedure gives relatively good results, where this method depends also on Eq. (17). This equation can be rewritten as a function of the wavelength $(c=v \lambda)$, as follows [71]:

$\frac{\alpha h c}{\lambda}=B \cdot\left(\frac{h c}{\lambda}-\frac{h c}{\lambda_{g a p}}\right)^{y}$

Where $\lambda_{g a p}, \boldsymbol{h}$, and $\boldsymbol{c}$ are the wavelength corresponding to the optical bandgap value, Planck's constant, and the velocity of light, respectively. In the case of the allowed direct transition $(y=1 / 2)$; so, Eq. (18) can be reformulated to become as follows:

$\left(\frac{\alpha}{\lambda}\right)^{2}=\left(B^{2}(h c)^{-1}\right) \times\left(\frac{1}{\lambda}-\frac{1}{\lambda_{\text {gap }}}\right)$

Subsequently, squaring this equation and let $\left(\mathbf{B}^{\mathbf{2}}(\mathbf{h c})^{-\mathbf{1}}\right)=K$, thereby,

$\left(\frac{\alpha}{\lambda}\right)^{2}=K\left(\frac{1}{\lambda}-\frac{1}{\lambda_{g a p}}\right)$

Thus, by representing a graphical relationship between $\left(\frac{1}{\lambda}\right)$ on the abscissa versus $\left(\frac{\alpha}{\lambda}\right)^{2}$ on the ordinate as illustrated in Fig. (8-a), by the linear extrapolation at $\frac{\mathbf{1}}{\lambda}=0$, we can obtain the value of $\boldsymbol{\lambda}_{\text {gap }}$, which expresses the wavelength corresponding to the direct band-gap energy of thin $\mathrm{ZnGa}_{2} \mathrm{~S}_{4}$ films of different thicknesses and thereafter recorded in Table 2. On the other hand, for the case of indirect allowed transition, let $\boldsymbol{y}=\mathbf{2}$, thus Eq. (18) becomes as follows:

$\frac{\alpha}{\lambda}=B / h c \cdot\left(\frac{1}{\lambda}-\frac{1}{\lambda_{g a p}}\right)^{2}$

By taking the square root of both sides and let $\sqrt{\boldsymbol{B} / \boldsymbol{h c}}=\boldsymbol{C}$, thus: 
$\sqrt{\alpha / \lambda}=C\left(\frac{1}{\lambda}-\frac{1}{\lambda_{g a p}}\right)$

Consequently, by graphical representation of the relationship between the value $(1 / \lambda)$ on the horizontal axis versus $\sqrt{\alpha / \lambda}$ on the vertical axis, as shown in Fig. (8-b). The linear extension of the straight line intersects the abscissa at a wavelength value that gives $\lambda_{\text {gap }}$ of the indirect band-gap energy of the $\mathrm{ZnGa}_{2} \mathrm{~S}_{4}$ thin films of different thicknesses and then the values have been recorded in Table 2.

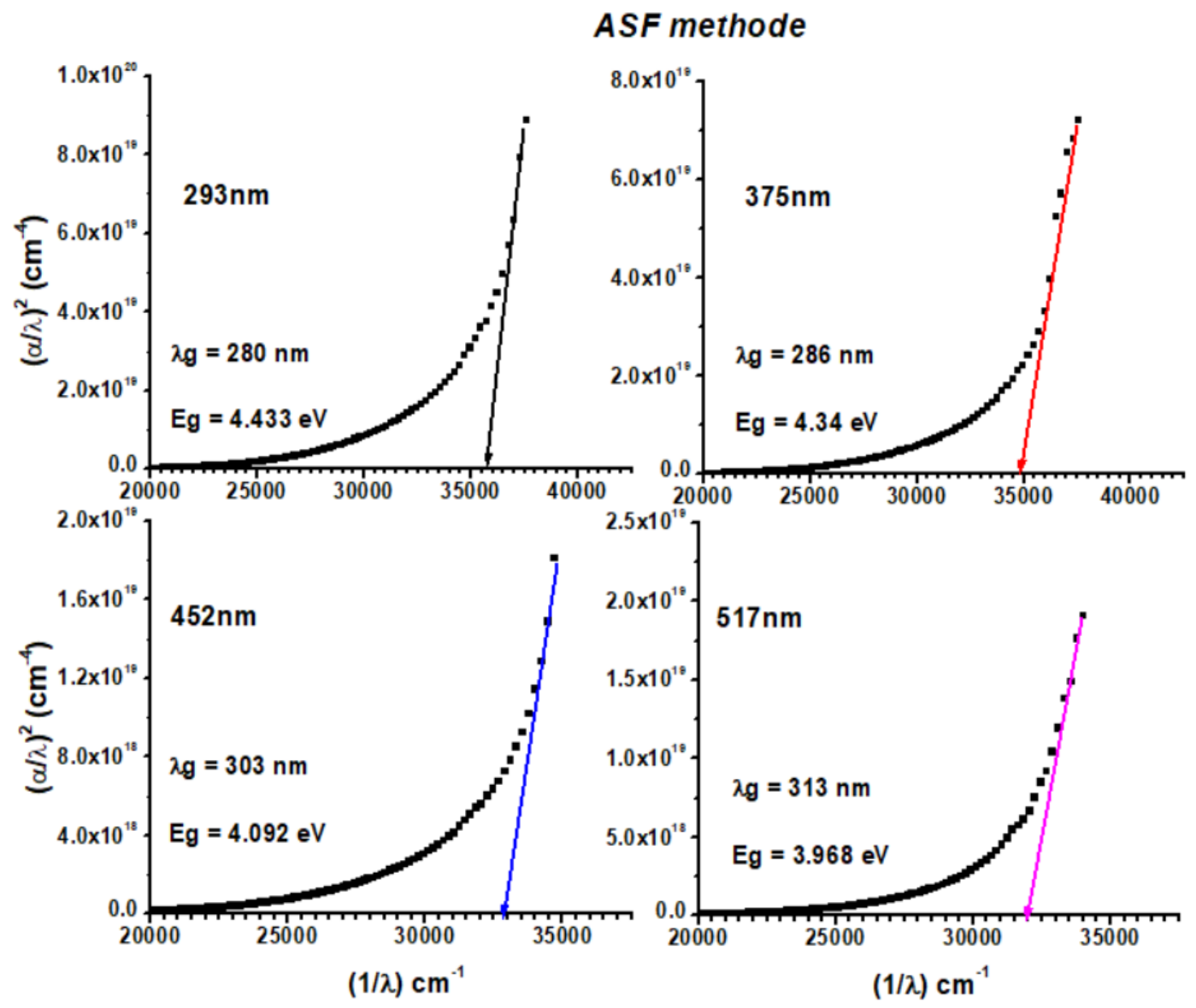

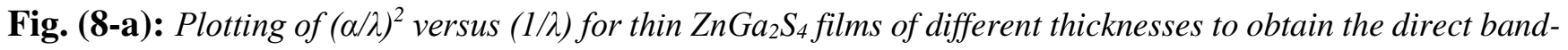
gap energy.

Table 3: The optical bandgap using different models and Urbach energies for the Novel $\mathrm{ZnGa}_{2} \mathrm{~S}_{4}$ thin films.

\begin{tabular}{|c|c|c|c|c|c|c|c|c|c|}
\hline \multirow{2}{*}{$\begin{array}{c}\text { Film } \\
\text { thickness } \\
\text { (nm) }\end{array}$} & \multicolumn{2}{|c|}{$\begin{array}{c}\text { Absorption spectrum fitting } \\
E_{g}(e V)\end{array}$} & \multicolumn{2}{|c|}{$\begin{array}{c}\text { Tauc's Plots } \\
E_{g}(e V)\end{array}$} & \multicolumn{2}{|c|}{$\begin{array}{c}\text { Cody Representations } \\
E_{g}(e V) \\
\end{array}$} & \multicolumn{2}{|c|}{$\begin{array}{c}\text { Davis-Mott model } \\
E_{g}(e V) \\
\end{array}$} & \multirow{2}{*}{$\begin{array}{c}\text { Urbach's } \\
\text { energy } \\
(\text { eV })\end{array}$} \\
\hline & Direct & Indirect & Direct & Indirect & Direct & Indirect & Direct & Indirect & \\
\hline 293 & 4.106 & 3.594 & 4.001 & 3.153 & 4.003 & 3.033 & 3.902 & 3.521 & 0.431 \\
\hline 375 & 4.018 & 3.447 & 3.979 & 3.122 & 3.972 & 2.951 & 3.853 & 3.403 & 0.531 \\
\hline 452 & 3.841 & 3.348 & 3.949 & 3.104 & 3.901 & 2.910 & 3.701 & 3.222 & 0.617 \\
\hline 517 & 3.754 & 3.221 & 3.902 & 3.051 & 3.854 & 2.901 & 3.682 & 3.103 & 0.699 \\
\hline
\end{tabular}

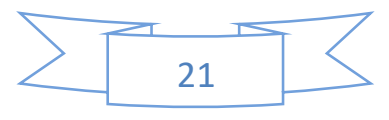




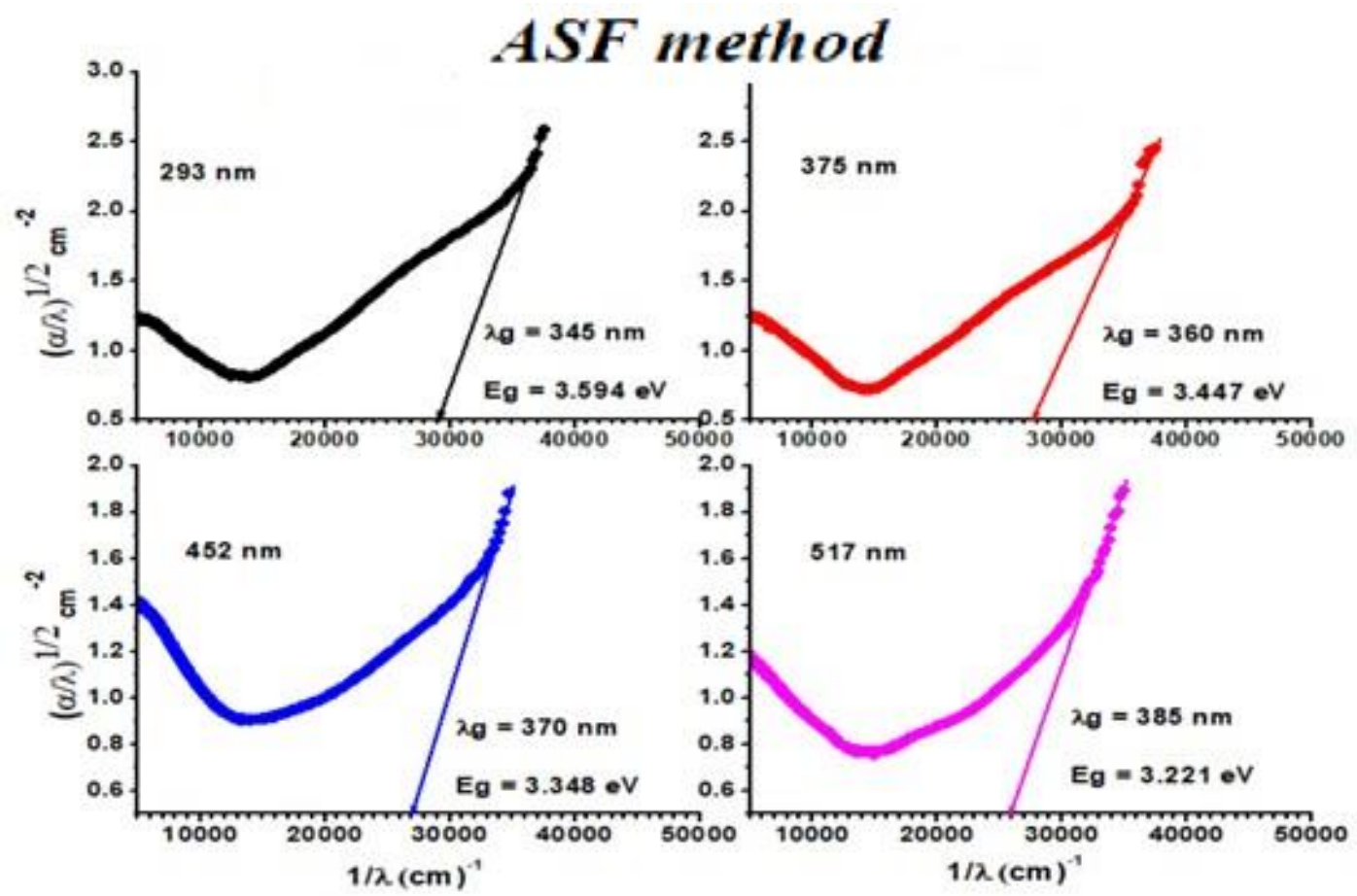

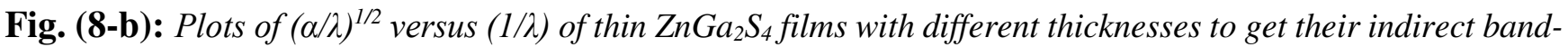
gap energy values.

It is clear that the wavelength value corresponding to the bandgap energy $\left(\lambda_{\text {gap }}\right)$ increases gradually from $280 \mathrm{~nm}$ to $313 \mathrm{~nm}$ for the direct transition and from $345 \mathrm{~nm}$ to $385 \mathrm{~nm}$ for the indirect one (Table 2). with the increase in the film thickness of the ternary compound $\mathrm{ZnGa}_{2} \mathrm{~S}_{4}$. While the direct and indirect gap energy values decrease gradually as the thickness increases, where the direct energy gap decreases from $4.106 \mathrm{eV}$ to $3.754 \mathrm{eV}$ and the indirect one decreases from $3.594 \mathrm{eV}$ to $3.221 \mathrm{eV}$, as recorded in Table 3. Moreover, the dependence of the direct energy gap upon the film thickness $(\boldsymbol{t})$ measured in $(\mathrm{nm})$ by using this method of the film samples of the ternary composition $\mathrm{ZnGa}_{2} \mathrm{~S}_{4}$ is illustrated in Fig. (12-a). The figure is linearly fitted to get the following experimental Eq.:

$E_{g}(e V)=4.603-1.65 \times 10^{-3} t(n m)$

\subsubsection{Tauc's Plots}

This most popular model allows us to derive the band gap energy $\boldsymbol{E}_{g}$ as a function of the incident photon energy $(\boldsymbol{E}=\boldsymbol{h} \boldsymbol{v})$ according to Eq. (17) [71]. The Tauc's optical band-gap associated with the thin films can be determined by extrapolating the linear trend observed in the spectral dependence of $(\boldsymbol{\alpha h v})^{2}$ and $(\boldsymbol{\alpha} \boldsymbol{h} \boldsymbol{v})^{1 / 2}$ over a finite range of photon energies $(\boldsymbol{h} \boldsymbol{v})$ [72]. The bandgap energy value of Tauc is obtained from the intersection of the linear portion of the curve with the abscissa [73]. Figs. (9-a) and (9-

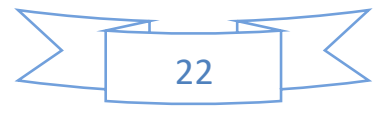


b) represent the plot of $(\boldsymbol{\alpha h} \boldsymbol{v})^{2}$ and $(\boldsymbol{\alpha h} \boldsymbol{v})^{1 / 2}$ versus photon energy $(\boldsymbol{h} \boldsymbol{v})$, respectively, to find the value of the allowed direct and allowed indirect band gap energies of the $\mathrm{ZnGa}_{2} \mathrm{~S}_{4}$ films of different thicknesses, which are prepared of different thicknesses. The extension of the straight-line segment of Figs. (9-a) and (9-b) with the abscissa (x-coordinate) gives the value of the direct and indirect gap energies, respectively for the studied $\mathrm{ZnGa}_{2} \mathrm{~S}_{4}$ samples.

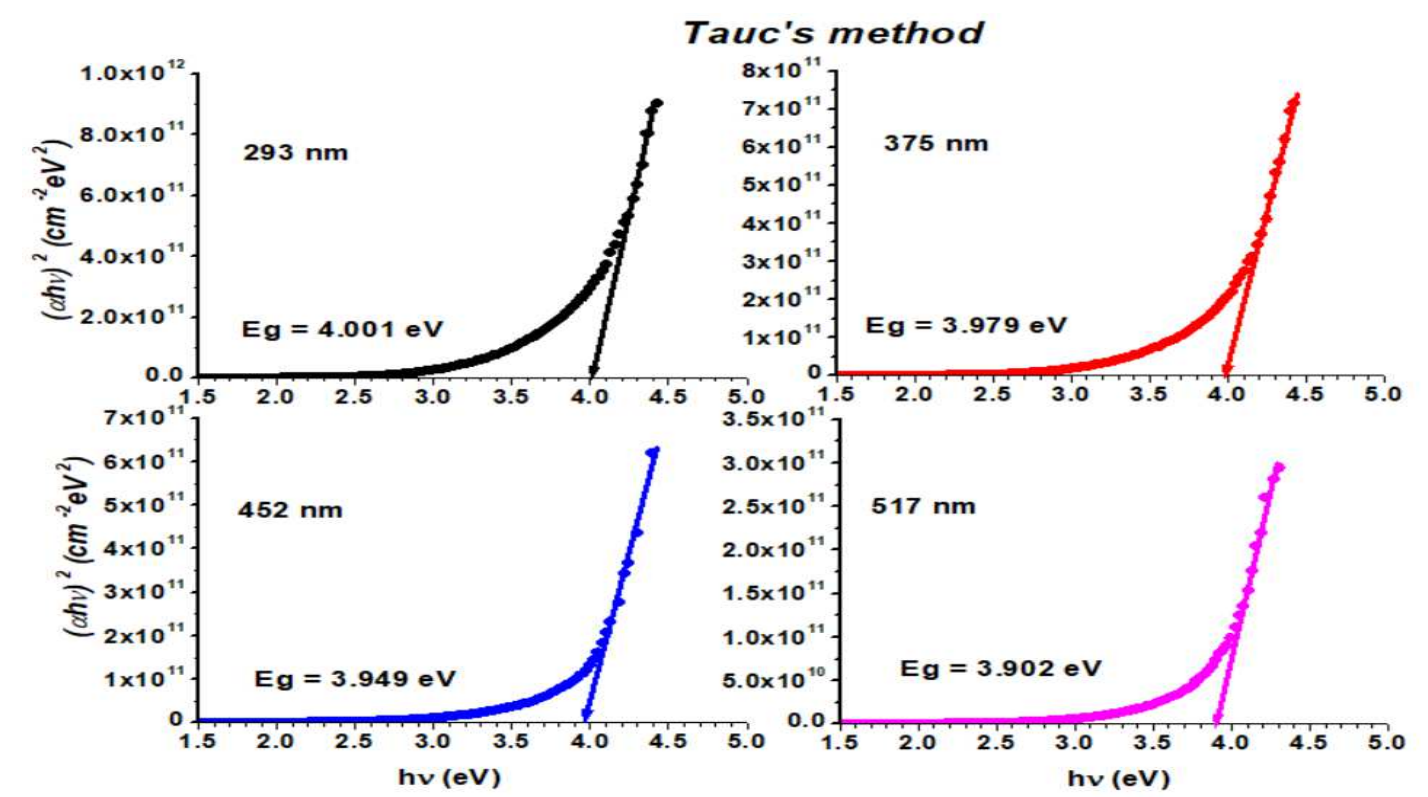

Fig. (9-a): The graphical relationship between $(\alpha h v)^{2}$ and $(h v)$ according to Tauc's plots for the ternary $\mathrm{ZnGa} \mathrm{S}_{4}$ thin film with different thicknesses.

The obtained values of the band gap energies of the present samples of different thicknesses are recorded in Table 3. It is noticeable that there is a slight change in the value of the two gap energies with the increase in thickness of the films. Where the direct band gap energy decreases from $4.001 \mathrm{eV}$ to become $3.902 \mathrm{eV}$, while decreases from $3.153 \mathrm{eV}$ to $3.051 \mathrm{eV}$. This deceasing in the energy gab values is due to the improvement in crystallization with the greater the thickness of the film. Moreover, the direct band gap energies are represented against the film thickness of $\mathrm{ZnGa}_{2} \mathrm{~S}_{4}$ composition, as depicted in Fig. (12-b), and the resultant was fitted linearly to get an empirical equation of a straight line that is given as:

$E_{g}(e V)=4.134-4.31 \times 10^{-4} t(n m)$. 


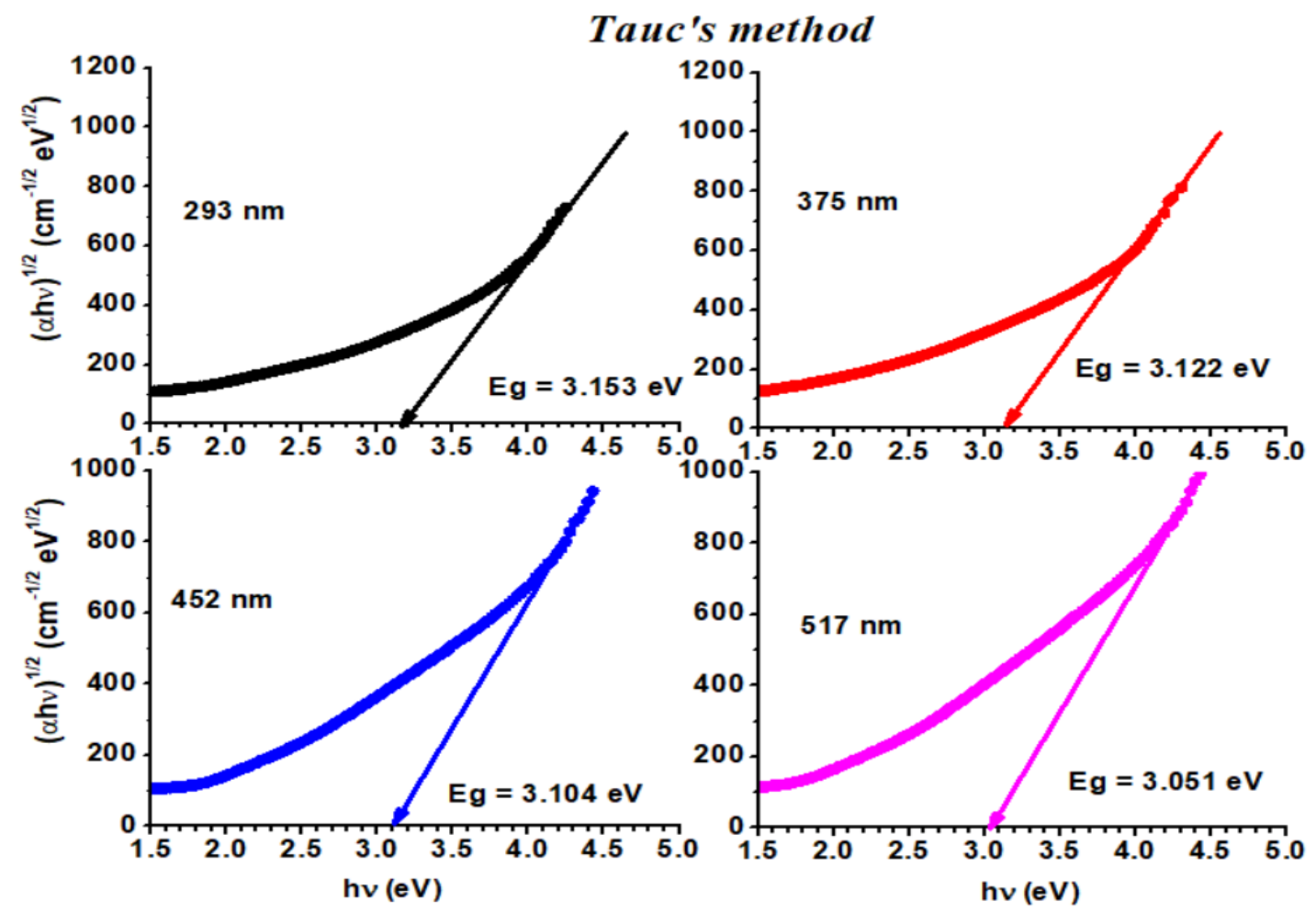

Fig. (9-b): The graphical relationship between (ahv) ${ }^{1 / 2}$ and (hv) according to Tauc's method for the ternary $\mathrm{ZnGa}_{2} \mathrm{~S}_{4}$ thin film with different thicknesses.

\subsubsection{Cody representations}

Cody assumed that the increasing value of Tauc's optical gap that is associated with the decrease in the thickness of films takes place owing to the curvature of the dependence of the spectra of the function $(\boldsymbol{\alpha h v})^{1 / 2}$ upon the energy of the incident photon, $\boldsymbol{f}(\boldsymbol{h} \boldsymbol{v})$ [74]. According to the model presented by Cody [75], the optical gap energy of the polycrystalline $\mathrm{ZnGa}_{2} \mathrm{~S}_{4}$ thin films of different thicknesses can be evaluated from the cut-cross of the extension of the linear part observed in the figure of representation of the spectra of $(\boldsymbol{\alpha} / \boldsymbol{h} \boldsymbol{v})^{2}$ or/and $(\boldsymbol{\alpha} / \boldsymbol{h} \boldsymbol{v})^{1 / 2}$ against $(\boldsymbol{h} \boldsymbol{v})$, along a limited range of the energy of the incident photons (the studied range). The intersection of this linear extension for the abscissa in accordance with the Cody model of the optical-band gap and to inferring the optical gap energy gives the band energy as shown in Figs. (10-a) and (10-b) for the allowed direct and indirect energy gap, respectively. Cody representations show a moderate curvature than those of Tauc's matches and a milder reliance in the optical gap associated with the thickness of thin $\mathrm{ZnGa}_{2} \mathrm{~S}_{4}$ films compared to the optical gap case of Tauc [72]. Tauc assumed that the component of the matrix of the momentum does not depend on the photon energy, and Cody proposes, while that the dipole matrix element does not actually depend on the energy of photons. Table 3 illustrates the estimated optical gap values using the Cody's model.

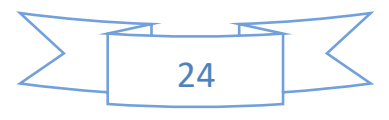




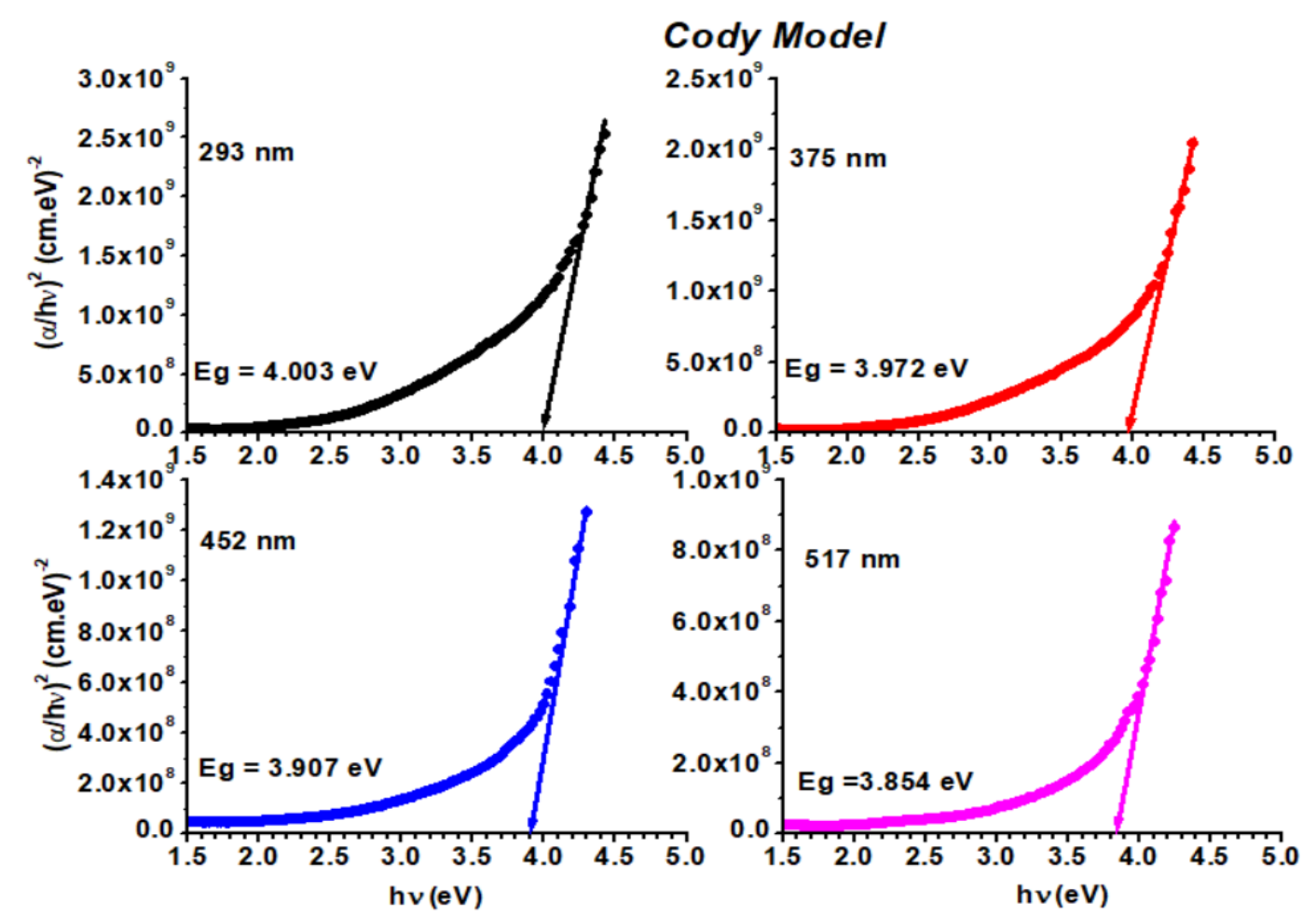

Fig. (10-a): Plots of the graphical relationship between $(\alpha / h v)^{2}$ versus $(h v)$ according to Cody model for the ternary compound $\mathrm{ZnGa}_{2} \mathrm{~S}_{4}$ thin film with different thicknesses.

The obtained results from these graphs showed that the energy of the allowed direct band gap decreases from $4.003 \mathrm{eV}$ to $3.854 \mathrm{eV}$, while for the indirect one, it decreases from 3.033 to become 2.901 $\mathrm{eV}$. Moreover, the direct gap energy is represented against the film thickness in Fig. (12-c), which is linearly fitted to get this linear Eq. between $\boldsymbol{E}_{\boldsymbol{g}}$ values and the thickness of films $(\boldsymbol{t})$ in $\mathrm{nm}$ :

$E_{g}(e V)=4.221-6.88 \times 10^{-4} t(n m)$.

Although slight differences in the band gap energy values can be noticed when making a comparison between the results obtained from applying Tauc 'plots and Cody's representations, it can neglect these differences if we take the measurement error range into account. Thus, it can conclude that these differences are not really important, so that use it. Generally, either model aims to compute the energy band gap for inorganic and organic semiconductors.

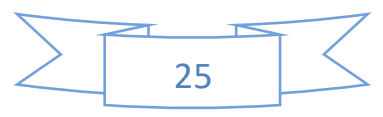



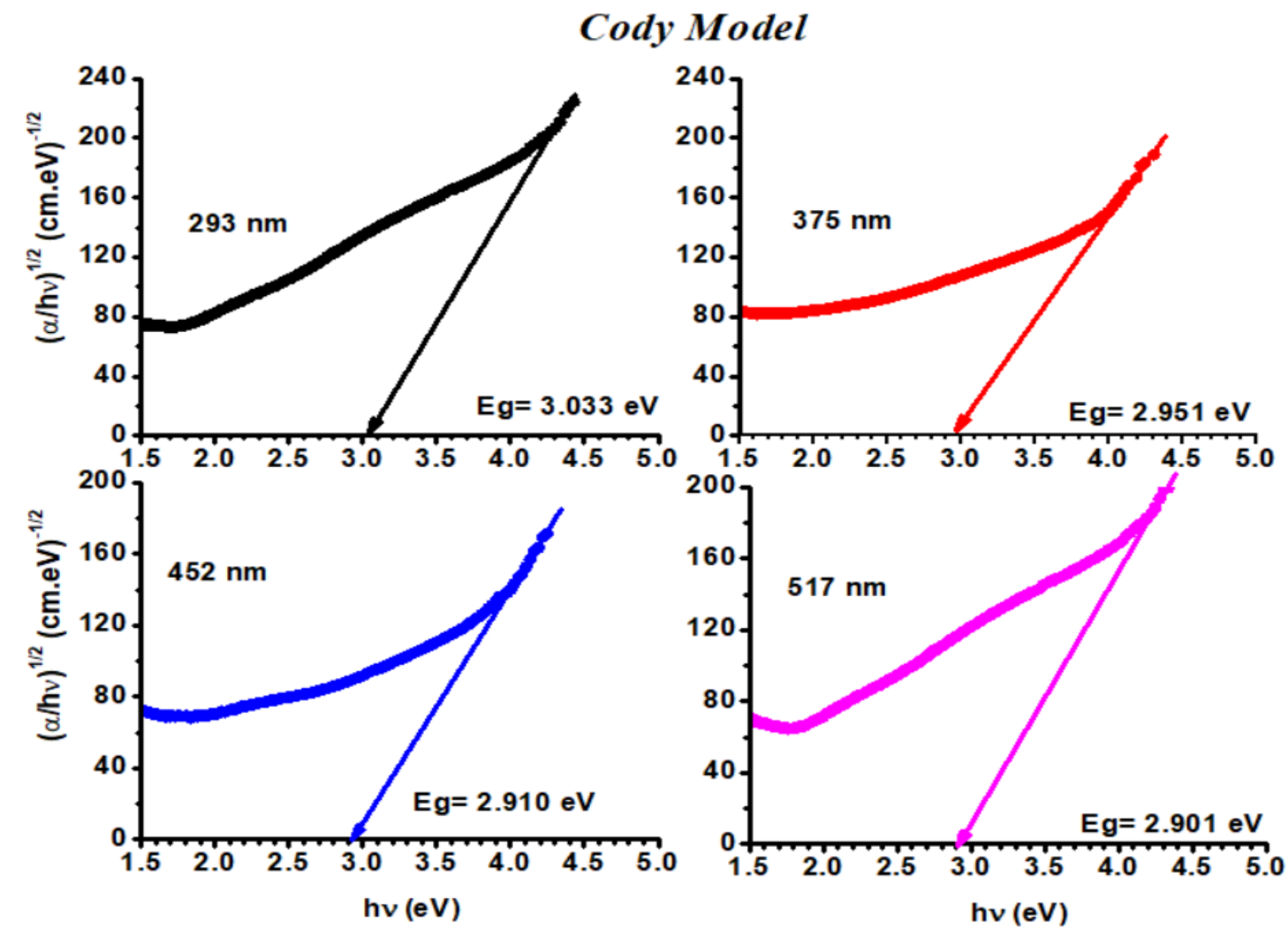

Fig. (10-b): Plot the graphical relationship between $(\alpha / h v)^{1 / 2}$ versus $h v$ according to Code model for the ternary compound $\mathrm{ZnGa}_{2} \mathrm{~S}_{4}$ thin film with different thicknesses.

\subsubsection{Davis-Mott model}

In the amorphous materials the density of hypothetical states is an unexpected equivalent, although it may be valid for states beyond $\boldsymbol{E}_{\boldsymbol{c}}$ and $\boldsymbol{E}_{\boldsymbol{v}}$ according to Davis and Mott model [76]. The density of state distributions may contribute to explaining the existence of three types of possible optical transitions according to the Mott-CFO model [77], which may contribute to the inter-band absorption. The matrix elements for these transitions are related to the spatial overlap between initial and final state wavefunctions. Davis and Mott showed that the matrix elements for transitions between extended states and those between weakly localized states. Accordingly, the absorption coefficient $(\boldsymbol{\alpha})$ is defined by the following relationship [77,78]:

$\alpha h v=\frac{4 \pi \sigma_{\min }}{3 n c(\Delta E)^{2}}\left(h v-E_{2}\right)^{3}$

Here $(\boldsymbol{n})$ is the index of the refraction of the investigated material, and $\boldsymbol{\sigma}_{\min }=\left(\frac{2 \pi^{3} c^{2} h^{3} a}{m^{2}}\right)\left[\boldsymbol{N}\left(\boldsymbol{E}_{c}\right)\right]^{2}$ is the minimum metallic conductivity. Thus, plotting $(\boldsymbol{\alpha} \boldsymbol{h} \boldsymbol{v})^{1 / 3}$ versus $(\boldsymbol{h} \boldsymbol{v})$ will give a straight line, subsequently, $\boldsymbol{E}_{2}$, which was produced from the cut-cross of the line to the abscissa, $(\boldsymbol{h} \boldsymbol{v})$-axis, i.e., when

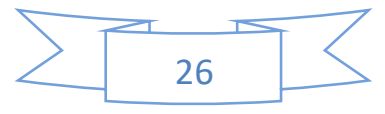


$\boldsymbol{\alpha h \boldsymbol { v }}=\mathbf{0}$ equals $\boldsymbol{E}_{2}=\boldsymbol{E}_{\boldsymbol{c}}-\boldsymbol{E}_{\boldsymbol{v}}$. Figs. (11-a) and (11-b) represent the relationship between $(\boldsymbol{\alpha h \boldsymbol { v }})^{1 / 3}$ versus $\boldsymbol{h} \boldsymbol{v}$ for the allowed direct electronic transition and $(\boldsymbol{\alpha} \boldsymbol{h} \boldsymbol{v})^{2 / 3}$ vs $(\boldsymbol{h} \boldsymbol{v})$ for the indirect one of thin $\mathrm{ZnGa}_{2} \mathrm{~S}_{4}$ films. The estimated values that deduced from these figures have been recorded in Table 3 for the direct and indirect gap energies.

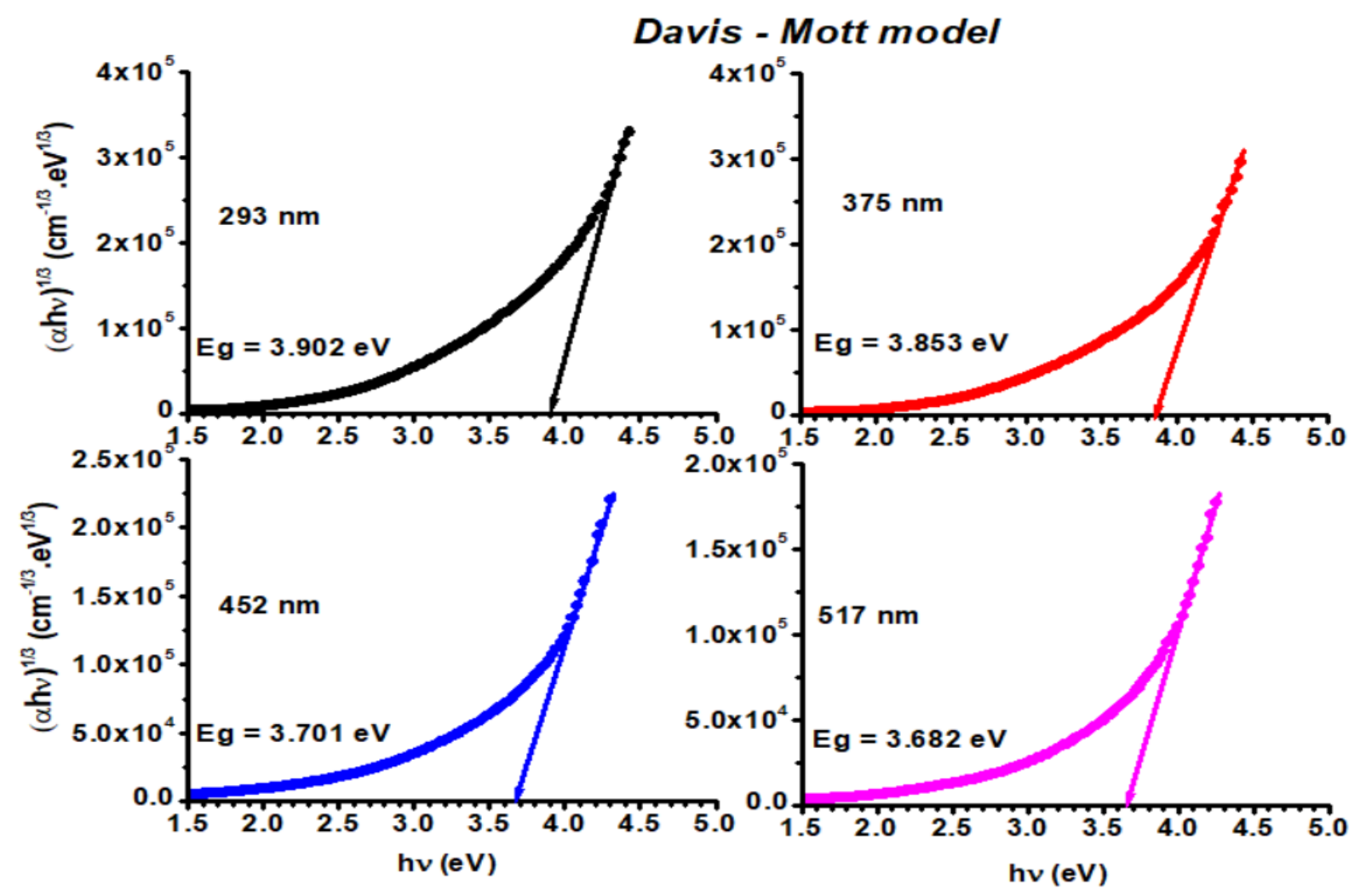

Fig. (11-a): The graphical relationship between $(\alpha h v)^{1 / 3}$ and $(h v)$, in accordance with the Davis-Mott model of the ternary $\mathrm{ZnGa}_{2} \mathrm{~S}_{4}$ thin film.

It can see that this model gives also results in the line with those obtained from the previous methods. The band gap energy values of the direct electronic transition decrease from $3.902 \mathrm{eV}$ to 3.682 $\mathrm{eV}$, while the indirect band gap energy values decrease from $3.521 \mathrm{eV}$ to $3,103 \mathrm{eV}$. Moreover, the direct band gap energy value has been also plotted graphically versus the film thickness, $t$ of the $\mathrm{ZnGa}_{2} \mathrm{~S}_{4}$ samples, as depicted in Fig. (12-d) for this case, and the graph was fitted to obtain an experimental linear Eq., gives as:

$E_{g}(e V)=4.230-1.09 \times 10^{-3} t(n m)$ 


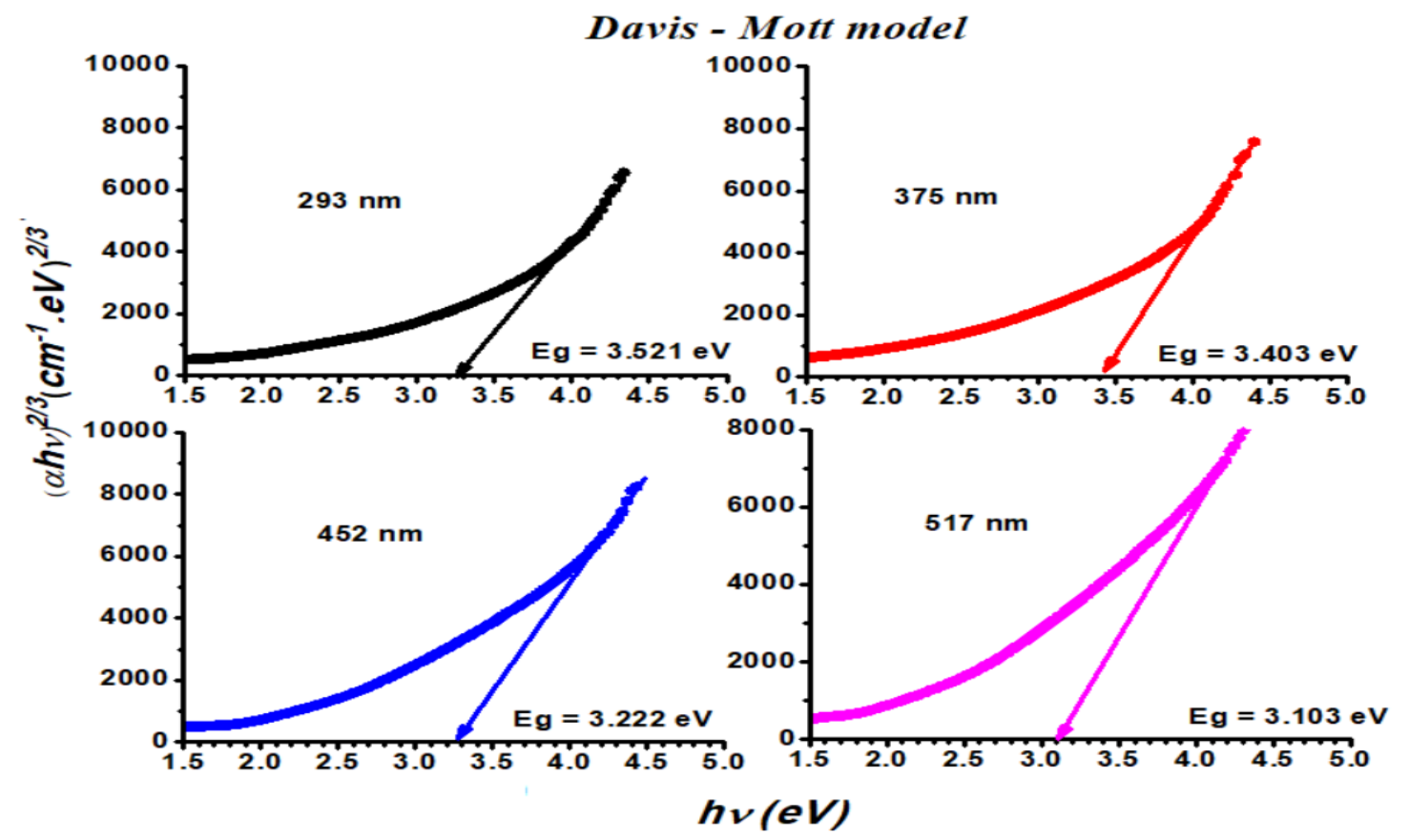

Fig. (11-b): The graphical relationship between $(\alpha h v)^{2 / 3}$ and $(h v)$ in accordance with Davis-Mott model for the ternary $\mathrm{ZnGa}_{2} \mathrm{~S}_{4}$ thin film.
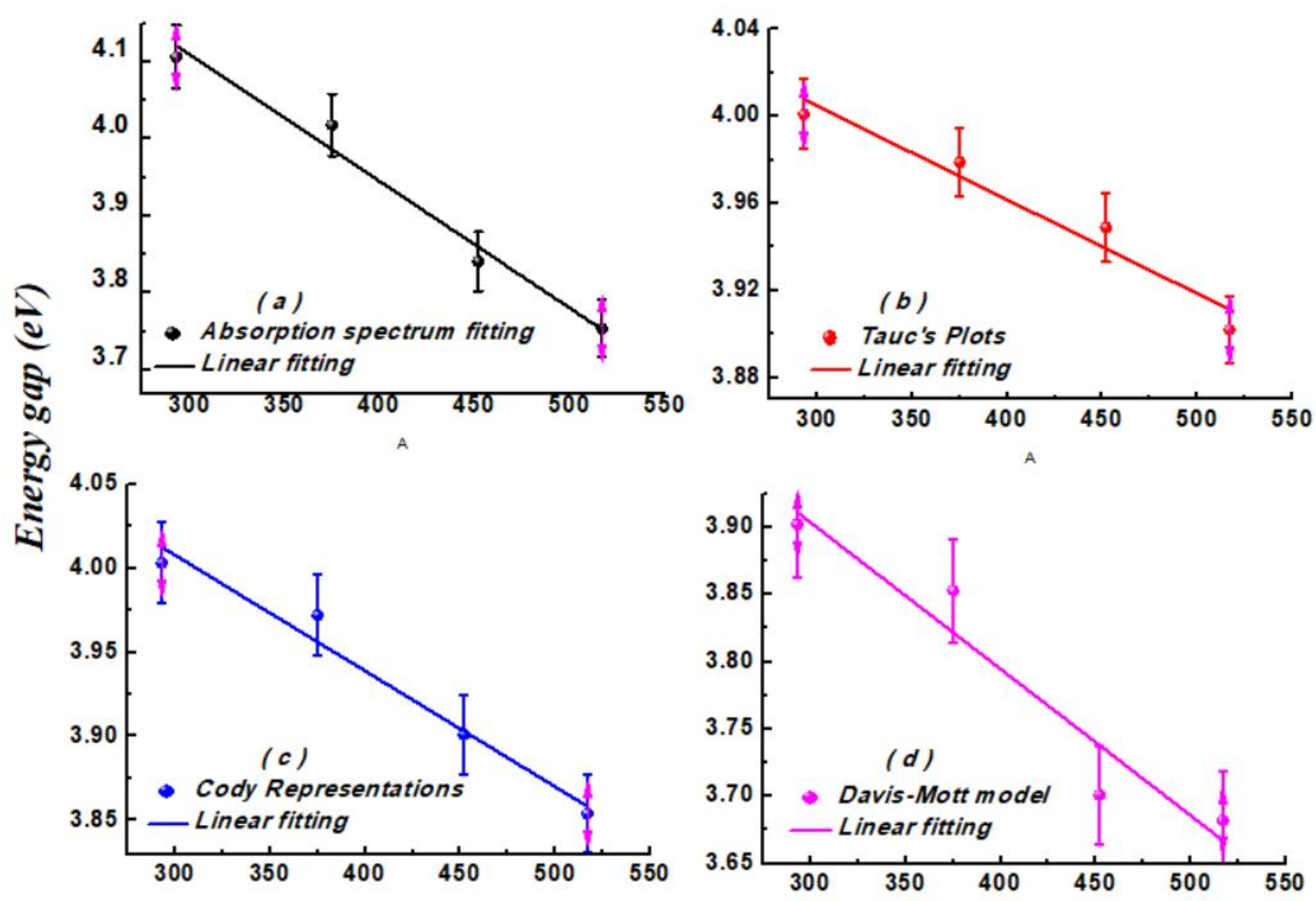

Film thickness (nm)

Fig. (12): The dependence of the direct optical energy gap upon the film thickness as computed by different methods for the ternary $\mathrm{ZnGa}_{2} \mathrm{~S}_{4}$ thin films.

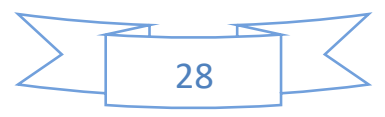


Consequently, by comparing the results of the determined energy gap values of the direct and indirect transitions measured by the different models with that of the Tauc's model, it is found that the ASF procedure ranges from $(-3.74) \%$ to $(+2.65) \%$. This difference is considered permissible in experimental measurements. Furthermore, the results of the Cody's model are completely identical to the results of the Tauc's model without a difference. While the Davis-Mott model has a ratio of differences in measurements ranging from $(-2.5) \%$ to $(-6.41) \%$ and this error percentage did not affect the results, absolutely. Therefore, it can be concluded that these four methods used in determining the energy gap of semiconductors are all considered accurate and reliable and the differences between them are practically acceptable.

\section{Conclusions}

Novel nanocrystalline $\mathrm{ZnGa}_{2} \mathrm{~S}_{4}$ thin films were fabricated with good quality using an inexpensive spray pyrolysis technique at different film thickness. XRD analysis showed that all samples are singlephase and have the polycrystalline quadrangular crystal structure. The degree of crystallinity and the volume fraction have been studied via x-ray diffractograms and the findings were that these parameters directly dependent on the thickness of the films.

The energy-dispersive $\mathrm{x}$-ray spectroscopy, EDAX is employed to investigate the elemental compositions of films and the result confirmed that all films have a good stoichiometry, along with in a good match with the theoretical computations. The field-emission-scanning electron microscope, FESEM was used to examine the morphology of the films' surfaces.

The optical transmittance and reflectance have been employed to investigate some important optical parameters such as absorption coefficient, Urbach energy, steepness parameters, and electronphonon interaction have been extensively studied and discussed.

The direct and indirect gap energy were also determined by different four models and compared with Tauc's model. The optical band gap values were slightly decreased if the film thickness increased, this is owing to the improvement of the crystallization process of films. The optical band gap energy of these films ranges from $4.106 \mathrm{eV}$ to $3.754 \mathrm{eV}$. This means than that these film samples are wide band gap semiconductors, which makes them strongly recommended for use in many optical applications as in thin-film solar cells and as a window layer.

\section{Funding}

The authors declare that this work does not receive any funding or financial support from any institution, but that they are who have borne all the expenses 


\title{
Declaration of competing interest
}

\author{
The authors declare that they have no conflict of interest.
}

\section{References}

[1] H.-J. Jeong, Y.-C. Kim, S.K. Lee, J.-H. Yun, J.-H. Jang, Enhanced spectral response of CIGS solar cells with antireflective subwavelength structures and quantum dots, Sol. Energy Mater. Sol. Cells. 194 (2019) 177-183.

[2] D.H. Kim, C.P. Muzzillo, J. Tong, A.F. Palmstrom, B.W. Larson, C. Choi, S.P. Harvey, S. Glynn, J.B. Whitaker, F. Zhang, Bimolecular Additives Improve Wide-Band-Gap Perovskites for Efficient Tandem Solar Cells with CIGS, Joule. 3 (2019) 1734-1745.

[3] W. Li, J.M.R. Tan, S.W. Leow, S. Lie, S. Magdassi, L.H. Wong, Recent Progress in Solution-Processed CopperChalcogenide Thin-Film Solar Cells, Energy Technol. 6 (2018) 46-59.

[4] R. Manivannan, S.N. Victoria, Preparation of chalcogenide thin films using electrodeposition method for solar cell applications-A review, Sol. Energy. 173 (2018) 1144-1157.

[5] D. Lilhare, A. Khare, Development of chalcogenide solar cells: Importance of CdS window layer, Opto-Electronics Rev. (2020) 43-63.

[6] A.S. Hassanien, A.A. Akl, Electrical transport properties and Mott's parameters of chalcogenide cadmium sulphoselenide bulk glasses, Journal of Non-Crystalline Solids, 432 (2016) 471-479.

[7] A.A. Akl, A.S. Hassanien, Microstructure and crystal imperfections of nanosized $\mathrm{CdS}_{\mathrm{x}} \mathrm{Se}_{1-\mathrm{x}}$ thermally evaporated thin films, Superlattices and Microstructures 85 (2015) 67-81.

[8] A.S. Hassanien, A. A. Akl, Estimation of some physical characteristics of chalcogenide bulk $\mathrm{Cd}_{50} \mathrm{~S}_{50-\mathrm{x}} \mathrm{Se}_{\mathrm{x}} \mathrm{glassy}$ systems, J. Non-Crystalline Solids 428 (2015) 112-120.

[9] G. Zhang, M. Zhu, L. Zhai, J. Cao, Z. Gao, T. Zeng, ThCr2Si2-type quaternary chalcogenides as efficient Pt-free counter electrodes for dye-sensitized solar cells, J. Alloys Compd. 817 (2020) 152797.

[10] A.S. Hassanien, A.A. Akl, Influence of thermal and compositional variations on conduction mechanisms and localized state density of amorphous $\mathrm{Cd}_{50} \mathrm{~S}_{50-\mathrm{x}} \mathrm{Se}_{\mathrm{x}}$ thin films, J. Non-Crystalline Solids, 487 (2018) 28-36.

[11] A.S. Hassanien, I Sharma, Optical properties of quaternary a-Ge ${ }_{15-x} \mathrm{Sb}_{\mathrm{x}} \mathrm{Se}_{50} \mathrm{Te}_{35}$ thermally evaporated thin-films: refractive index dispersion and single oscillator parameters, Optik, 200 (2020) 163415.

[12] A.S. Hassanien, Ishu Sharma, A.A. Akl, Physical and optical properties of a-Ge-Sb-Se-Te bulk and film samples: Refractive index and its association with electronic polarizability of thermally evaporated a-Ge $\mathrm{Ge}_{15-\mathrm{x}} \mathrm{Sb}_{\mathrm{x}} \mathrm{Se}_{50} \mathrm{Te}_{35}$ thin-films, J. Non- crystalline Solids 531 (2020) 119853.

[13] A.S. Hassanien, A.A. Akl, X-Ray Studies: $\mathrm{CO}_{2}$ pulsed laser annealing effects crystallography, microstructure and crystal defects vacuum deposited nanocrystalline ZnSe thin films, CrystEngComm, 20 (2018) 7120-7129.

[14] J. Zhang, W. Lian, Y. Yin, X. Wang, R. Tang, C. Qian, X. Hao, C. Zhu, T. Chen, All Antimony Chalcogenide Tandem Solar Cell, Sol. RRL. 4 (2020) 2000048.

[15] A.S. Hassanien, K.A. Aly, A.A. Akl, Optical properties of thermally evaporated ZnSe thin films annealed at different pulsed leaser powers, J. Alloys and Compounds, 685 (2016) 733-742.

[16] A.S. Hassanien, R. neffati, K.A. Aly, Impact of Cd-addition upon optical properties and dispersion parameters of thermally evaporated $\mathrm{Cd}_{\mathrm{x}} \mathrm{Zn}_{1-\mathrm{x}}$ Se films: Discussions on bandgap engineering, conduction and valence band positions, Optik,212 (2020) 164681.

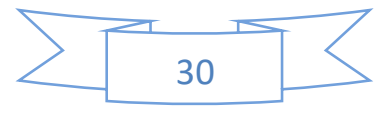


[17] A.S. Hassanien, Ishu Sharma, Band-gap engineering, conduction and valence band positions of thermally evaporated amorphous $\mathrm{Ge}_{15-\mathrm{x}} \mathrm{Sb}_{\mathrm{x}} \mathrm{Se}_{50} \mathrm{Te}_{35}$ thin films: Influences of $\mathrm{Sb}$ upon some optical characterizations and physical parameters, Journal of Alloys and compounds 798 (2019) 750-763.

[18] M. Nadarajah, K.S. Gour, V.N. Singh, Sputtered Cadmium Sulfide (CdS) Buffer Layer for Kesterite and Chalcogenide Thin Film Solar Cell (TFSC) Applications, J. Nanosci. Nanotechnol. 20 (2020) 3909-3912.

[19] A. Stoliaroff, A. Lecomte, O. Rubel, S. Jobic, X. Zhang, C. Latouche, X. Rocquefelte, Deciphering the Role of Key Defects in $\mathrm{Sb}_{2} \mathrm{Se}_{3}$, a Promising Candidate for Chalcogenide-Based Solar Cells, ACS Appl. Energy Mater. 3 (2020) 24962509.

[20] K.S. Gour, R. Parmar, R. Kumar, V.N. Singh, Cd-Free Zn (O, S) as Alternative Buffer Layer for Chalcogenide and Kesterite Based Thin Films Solar Cells: A Review, J. Nanosci. Nanotechnol. 20 (2020) 3622-3635.

[21] A.A. AKL, I.M. El Radaf, A.S. Hassanien, Intensive comparative study using X-Ray diffraction for investigating microstructural parameters and crystal defects of the novel nanostructural $\mathrm{ZnGa}_{2} \mathrm{~S}_{4}$ thin films, Superlattices and Microstructures, 143 (2020) 106544.

[22] I. M. El Radaf, H. Y. S. Al-Zahrani, A.S. Hassanien, Novel synthesis, structural, linear and nonlinear optical properties of p-type kesterite nanosized $\mathrm{Cu}_{2} \mathrm{MnGeS}_{4}$ thin films, J. Materials Science: Materials in Electronics, 31 (2020) 8336-8348, https://doi.org/10.1007/s10854-020-03369-9

[23] A.A. Akl, S.A. Mahmoud, S.M Al Shomar, A.S. Hassanien, improving microstructural properties and minimizing crystal imperfections of nanocrystalline $\mathrm{Cu}_{2} \mathrm{O}$ thin films of different solution molarities for solar cell applications, Materials Science in Semiconductor Processing, 74 (2018) 183-192.

[24] A.S. Hassanien, A. A. Akl, Microstructure and crystal imperfections of nano-crystalline sprayed iridium oxides thin films, Physica B: 473 (2015) 11-19.

[25] Alaa A. Akl; Microstructure and electrical properties of iron oxide thin films deposited by spray pyrolysis; Applied Surface Science 221 (2004) 319-329.

[26] Peterlin A. Molecular model of drawing polyethylene and polypropylene, J. Materials Science, 6 (1971) 490-508.

[27] Bowden PB, Young RJ. Deformation mechanisms in crystalline polymers. J. Materials Science, 9 (1974) 2034-2051.

[28] J.M. Haudin, Plastic deformation of semi-crystalline polymers. In: Escaig B, G'Sell C, editors. Plastic deformation of amorphous and semi-crystalline materials. Les Ulis : Les Editions de Physique, (1982) 291-311.

[29] Lin L, Argon AS. Structure and plastic deformation of polyethylene. J. Materials Science 29 (1994) 294-323.

[30] J. Jia, D. Raabe; Crystallinity and Crystallographic Texture in Isotactic Polypropylene during Deformation and Heating; Soft Condensed Matter; 14 November (2008)1-19, arXiv:0811.2412

[31] A. Weidinger, P.H. Hermans, On the determination of the crystalline fraction of isotactic polypropylene from $\mathrm{x}$-ray diffraction. Macromol Chemical Physics, 50 (1961) 98-115.

[32] S.A. Mahmoud, A.A. Akl, S.M. Al-Shomar, Effect of some preparative parameters on optical properties of spray deposited iridium oxide thin films, Physica B, 404 (2009) 2151-2158.

[33] B.D. Cullity, Elements of X-ray diffraction, 2nd edn. (1978) Addison-Wesley, London.

[34] J.T. Bonarski, W. Olek, Application of the crystalline volume fraction for characterizing the ultrastructural organization of wood, Cellulose, 18 (2011) 223-235.

[35] S. Huang, Structure and Structure Analysis of Amorphous Materials 1984 (Claredon, Oxford).

[36] X. Y. Zhang, F. X. Zhang, J. W. Zhang, W. Yu, M. Zhang, J. H. Zhao, R. P. Liu, Y. F. Xu, and W. K. Wang, Influence of pressures on the crystallization process of an amorphous $\mathrm{Fe}_{73.5} \mathrm{Cu}_{1} \mathrm{Nb}_{3} \mathrm{Si}_{13.5} \mathrm{~B}_{9}$ alloy J. Appl. Phys. 84 (1998) 1918.

[37] T. Gloriant, M. Gich, S. Suri ach, M. D. Baro, and A. L. Greer, Evaluation of the Volume Fraction Crystallised during Devitrification of Al-Based Amorphous Alloys, Materials Science Forum 343-346 (2000) 365.

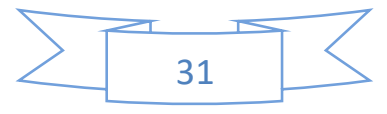


[38] G.E. Abrosimov, A.S. Aronin, and N.N. Kholstinina, On the determination of the volume fraction of the crystalline phase in amorphous-crystalline alloys, Physics of the Solid State, 52, 3 (2010) $445-451$.

[39] L.C. Zhang, Z.Q. Shen, and J. Xu, J. Materials Research, Glass formation in a (Ti, Zr, Hf)-(Cu, Ni, Ag)-Al high-order alloy system by mechanical alloying, 18, 9 (2003) 2141-2149.

[40] C. Das, S. Ray, Thin Solid Films, Onset of microcrystallinity in silicon thin films, 403 - 404 (2002) 81-85.

[41] T. Sameshima, K. Saitoh, N. Aoyama, S. Higashi, M. Kondo, A. Matsuda, Electrical Properties of Pulsed Laser Crystallized Silicon Films, Japan. J. Applied Physics 38, 48 (1999) 1892.

[42] Alaa A. Ak, Influence of preparation conditions on the dispersion parameters of sprayed iron oxide thin films, Applied Surface Science 256 (2010) 7496-750.

[43] Alaa A. Akl, Optical properties of crystalline and non-crystalline iron oxide thin films deposited by spray pyrolysis, Applied Surface Science 233 (2004) 307-319

[44] J. Song, Y. He, J. Chen, D. Zhu, Z. Pan, Y. Zhang, J.-a. Wang, Bicolor lightemitting diode based on zinc oxide nanorod arrays and poly (2-methoxy, 5- octoxy)-1, 4-phenylenevinylene, Journal of electronic materials, 41 (2012) 431- 436.

[45] A.S. Hassanien, H.R. Alamri, I.M. El Radaf, Impact of film thickness on optical properties and optoelectrical parameters of novel $\mathrm{CuGaGeSe}_{4}$ thin films synthesized by electron beam deposition, Optical and Quantum Electronics 52, (2020) 335.

[46] F. Urbach, The long-wavelength edge of photographic sensitivity and of the electronic absorption of solids, Physical Review, 92 (1953) 1324.

[47] O.S. Heavens, Optical Properties of Thin Films, Dover, New York, 1965; O.S. Heavens, Thin Film Physics, Methuen, London, 1970

[48] M. Born, E. Wolf, Principles of Optics, (1983) Pergamon Press, Oxford.

[49] A.S. Hassanien, A. A. Akl, Optical characteristics of iron oxide thin films prepared by spray pyrolysis technique at different substrate temperatures, Applied Physics A: Materials Science and Processing, 124 (2018) 752.

[50] M. Mohamed, E.R. Shaaban, M. N. Abd-el Salam, A.Y. Abdel-Latief, S.A. Mahmoud, M.A. Abdel-Rahim, Investigation of the optical and electrical parameters of $\mathrm{As}_{47.5} \mathrm{Se}_{47.5} \mathrm{Ag}_{5}$ thin films with different thicknesses for optoelectronic applications, Optik, 178, (2019) 1302-1312.

[51] M.S. Zoromba, M. Tashkandi, A. Alshehri, M. Abdel-Aziz, M. Bassyouni, S. A. Mahmoud, A.B. Slimane, A. AlHossainy, Polymer solar cell based on doped oanthranilic acid and o-aminophenol copolymer, Optical Materials, 104 (2020) 109947.

[52] M.S. Zoromba, M. Tashkandi, A. Alshehri, M. Abdel-Aziz, M. Bassyouni, S. A. Mahmoud, A.B. Slimane, A. AlHossainy, Polymer solar cell based on doped oanthranilic acid and o-aminophenol copolymer, Optical Materials, 104 (2020) 109947.

[53] H.L. Mansour, K.A. Mishjil, N.F. Habubi, S.S. Chiad, Structural and Optical Properties of $\mathrm{Cd}_{0.4} \mathrm{Se}_{0.6}$, Thin Films Prepared by CBD, Thin Film Science and Technology, 3 (2014) 57-60.

[54] A.S. Hassanien, A.A. Akl, Optical characterizations and refractive index dispersion parameters of annealed $\mathrm{TiO}_{2}$ thin films synthesized by RF-sputtering technique at different flow rates of the reactive oxygen gas, Physica B, 576 (2020) 411718.

[55] A.L. Allred, Electronegativity values from thermochemical data, J. Inorganic and nuclear chemistry, 17 (1961) 215-221.

[56] A.S. Hassanien, Studies on dielectric properties, opto-electrical parameters, and electronic polarizability of thermally evaporated amorphous $\mathrm{Cd}_{50} \mathrm{~S}_{50-\mathrm{x}} \mathrm{Se}_{\mathrm{x}}$ thin films, J. Alloys Compounds, 671 (2016) 566-578.

[57] E.A. Davis, N. Mott, Electronic processes in non-crystalline materials (1971) Clarendon Press Oxford.

[58] A.S. Hassanien, A. A. Akl, Effects of Se on optical and electrical properties of chalcogenide CdSSe thin films, Superlattices and Microstructures, 89 (2016) $153-169$. 
[59] H. Khmissi, S.A. Mahmoud, A.A. Akl, Investigation of thermal annealing effect on the microstructure, morphology, linear and non-linear optical properties of spray deposited nanosized $\mathrm{V}_{2} \mathrm{O}_{5}$ thin films, Optik, 227 (2021) 165979.

[60] T.E Whall, K.K. Yeung, Y.G. Proykova, V.A. M Brabers, Electrical conductivity and thermoelectric power of nickel ferrous ferrite Variable-range hopping and the Coulomb gap, Philosophical Magazine B, 54 (1986) 505-521.

[61] J. Melsheimer, D. Ziegler, Band gap energy and Urbach tail studies of amorphous, partially crystalline and polycrystalline tin dioxide, Thin Solid Films, 129 (1985) 35-47.

[62] S.J. Ikhmayies, R.N. Ahmad-Bitar, A study of the optical bandgap energy and Urbach tail of spray-deposited CdS: In thin films, Journal of Materials Research and Technology, 2 (2013) 221-227.

[63] K.A. Aly, A.A. Elnaeim, M. Uosif, O. Abdel-Rahim, Optical properties of Ge-As- Te thin films, Physica B: Condensed Matter, 406 (2011) 4227-4232.

[64] S. Ikhmayies, R. Ahmad-Bitar, Thickness dependence of the bandgap energy and Urbach tail for CdS thin films prepared by vacuum evaporation, in: Proceedings of the eleventh World renewable energy congress and exhibition, (2010) 979984.

[65] L. Kazmerski, Polycrystalline and amorphous thin films and devices, Elsevier, 2012.

[66] J. Chaudhari, N. Deshpande, Y. Gudage, A. Ghosh, V. Huse, R. Sharma, Studies on growth and characterization of ternary $\mathrm{CdS}_{1-\mathrm{x}} \mathrm{Se}_{\mathrm{x}}$ alloy thin films deposited by chemical bath deposition technique, Applied Surface Science, 254 (2008) 6810- 6816.

[67] R. Mariappan, V. Ponnuswamy, M. Ragavendar, Characterization of $\mathrm{CdS}_{1-x} \mathrm{Se}_{\mathrm{x}}$ thin films by chemical bath deposition technique, Optik, 123 (2012) 1196-1200.

[68] A. Abdel-Latif, H.M. Kotb, M. Hafiz, M. Dabban, Influence of heat treatment on the structural, optical and electrical properties of $\mathrm{Cd}_{20} \mathrm{Sn}_{10} \mathrm{Se}_{70}$ thin films, Materials Science in Semiconductor Processing, 30 (2015) 502-512.

[69] A.S. Hassanien, I.M. El radaf, A.A. Akl, Physical and optical studies of the novel non-crystalline $\mathrm{Cu}_{\mathrm{x}} \mathrm{Ge}_{20-\mathrm{x}} \mathrm{Se}_{40} \mathrm{Te}_{40}$ bulk glasses and thin films, J. Alloys and Compounds, 849 (2020) 156718.

[70] N. Ghobadi; International Nano Letters;" Band gap determination using absorption spectrum fitting procedure" 2013, 3:2; http://www.inl-journal.com/content/3/1/2

[71] J. Tauc, A. Menth, States in the gap. J Non-Crystalline Solids, 8-10 (1972) 569-585.

[72] N. Laidani, R. Bartali, , G. Gottardi, M. Anderle, P.Cheyssac, Optical absorption parameters of amorphous carbon films from forouhi-bloomer and tauc-lorentz models: A comparative study, J. Physics Condensed Matter, 20 (1) (2007) 015216.

[73] O'Learly, S.K.; Lim, P.K. On determining the optical GAP associated with an amorphous semiconductor: A generalization of the Tauc model. Solid State Community, 104 (1997) 17-21, 2.

[74] T.M. Mok, S.K. O'Leary, The dependence of the Tauc and Cody optical gaps associated with hydrogenated amorphous silicon on the film thickness: $\alpha$ l Experimental limitations and the impact of curvature in the Tauc and Cody plots. J. Applied Physics, 102 (2007) 113525: 1-9.

[75] G.D. Cody, Hydrogenated Amorphous Silicon, Part B: Optical Properties, Semiconductors and Semimetals, 1st ed.; Pankove, J.I., Ed.; Academic Press: Orlando, FL, USA, (1984) V 21.

[76] N.F. Mott, E.A. Davis, Electron processes in non-crystalline materials (1979) Clarendon, Oxford.

[77] E.N. Economou, M.H.Cohen, Anderson's theory of localization and the Mott-CFO model, Material Research Bulletin, $5,8,(1970) 577-590$.

[78] N. F. Mott, Metal-Insulator Transition, Review of Modern Physics, 40 (1968) 677.

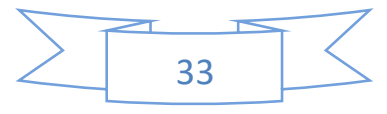




\section{Figures}
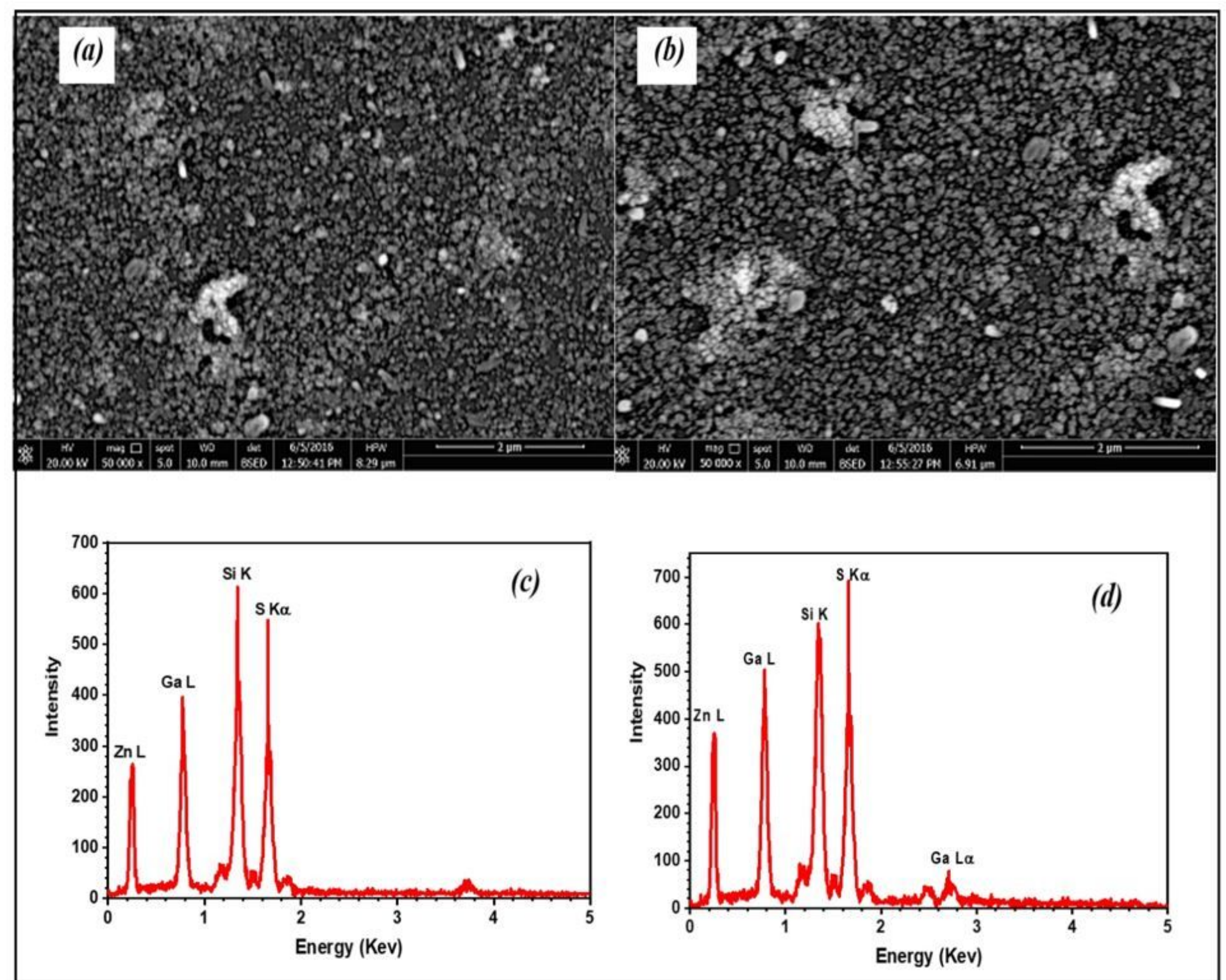

Figure 1

FE-SEM micrographs ( $a$ and $b$ ) and EDS-spectra ( $c$ and $d$ ) of the present thinner and thicker film samples (of thicknesses $293 \mathrm{~nm}$ and $517 \mathrm{~nm}$ ), as typical samples of the ZnGa2S4 thin films. 

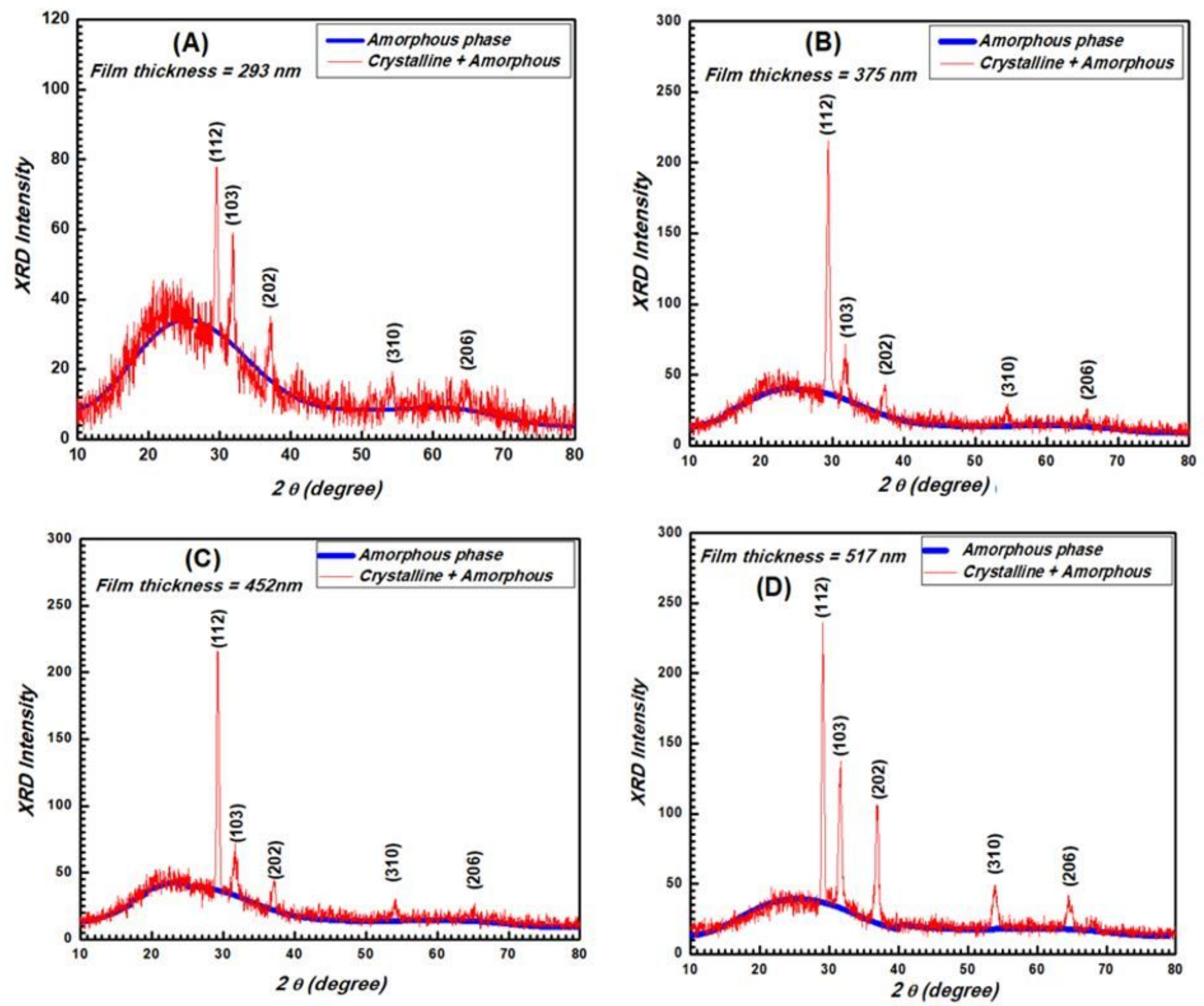

Figure 2

X-ray diffraction pattern of the ZnGa2S4 thin films of different thickness; The Red line represents the experimental curve (it is a mixture of the amorphous and crystalline phases), while Blue line is the amorphous phase. 


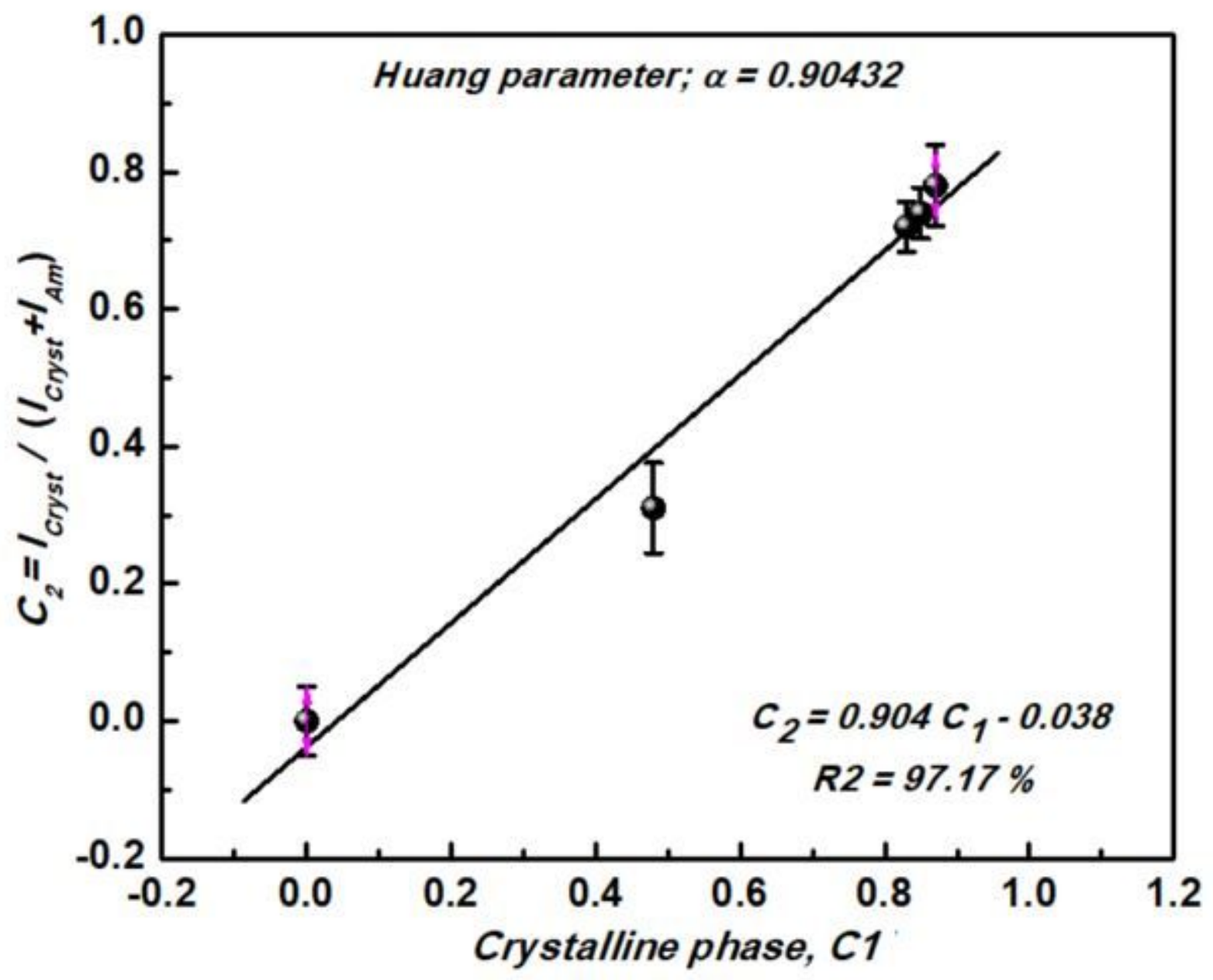

Figure 3

Dependence of intensity's ratios for the integrated intensities on the true $\mathrm{C} 1$ concentration of the crystalline phase, the slope of the straight line represents the a-coefficient (Huang parameter).
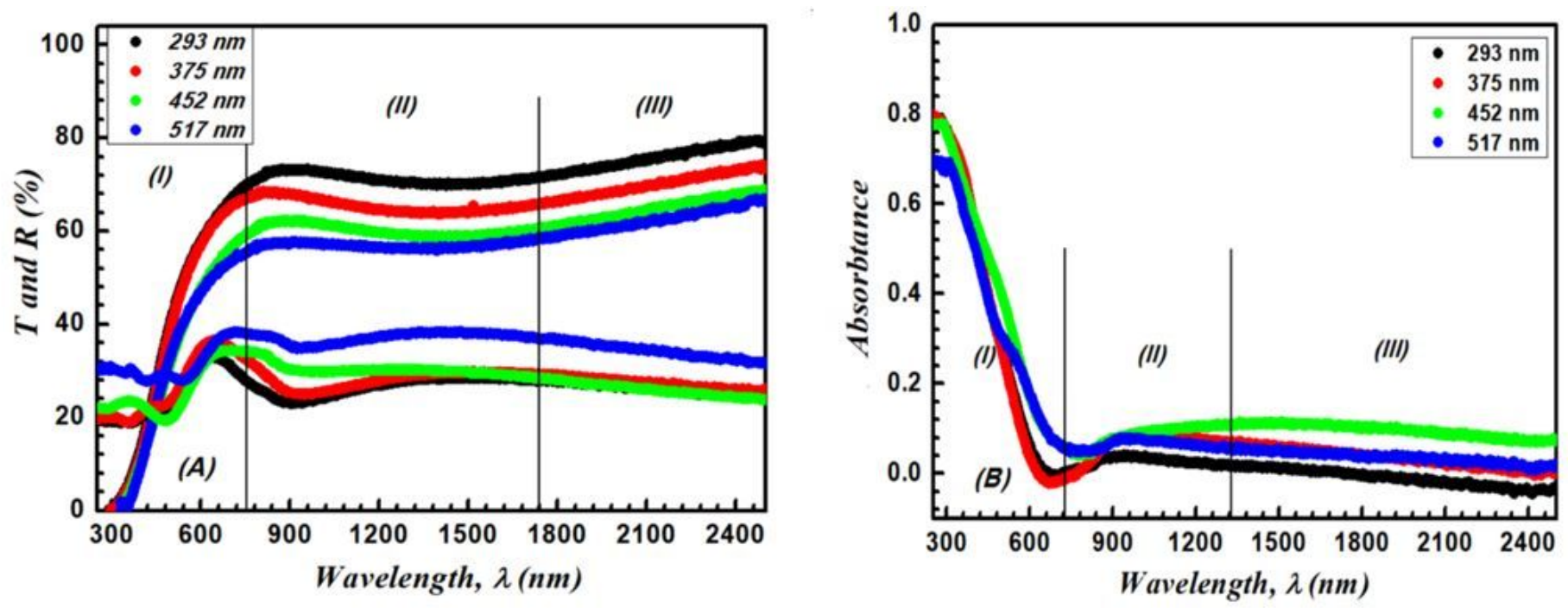

Figure 4 
The spectral variations of (a) transmittance and reflectance, and (b) absorbance as functions of the wavelength incident on thin ZnGa2S4 films.
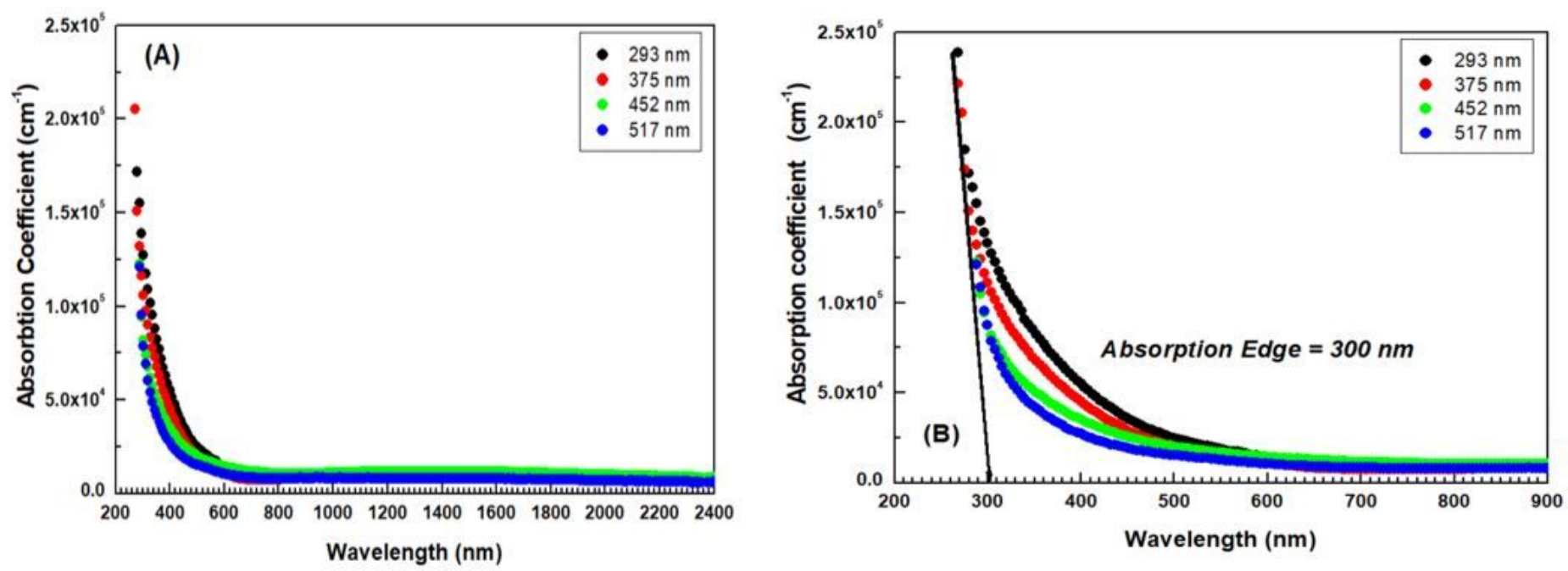

Figure 5

The variation of the absorption coefficient versus the wavelength of thin $\mathrm{ZnGa2S} 4$ films (a) along the studied range and (b) at the absorption edge.
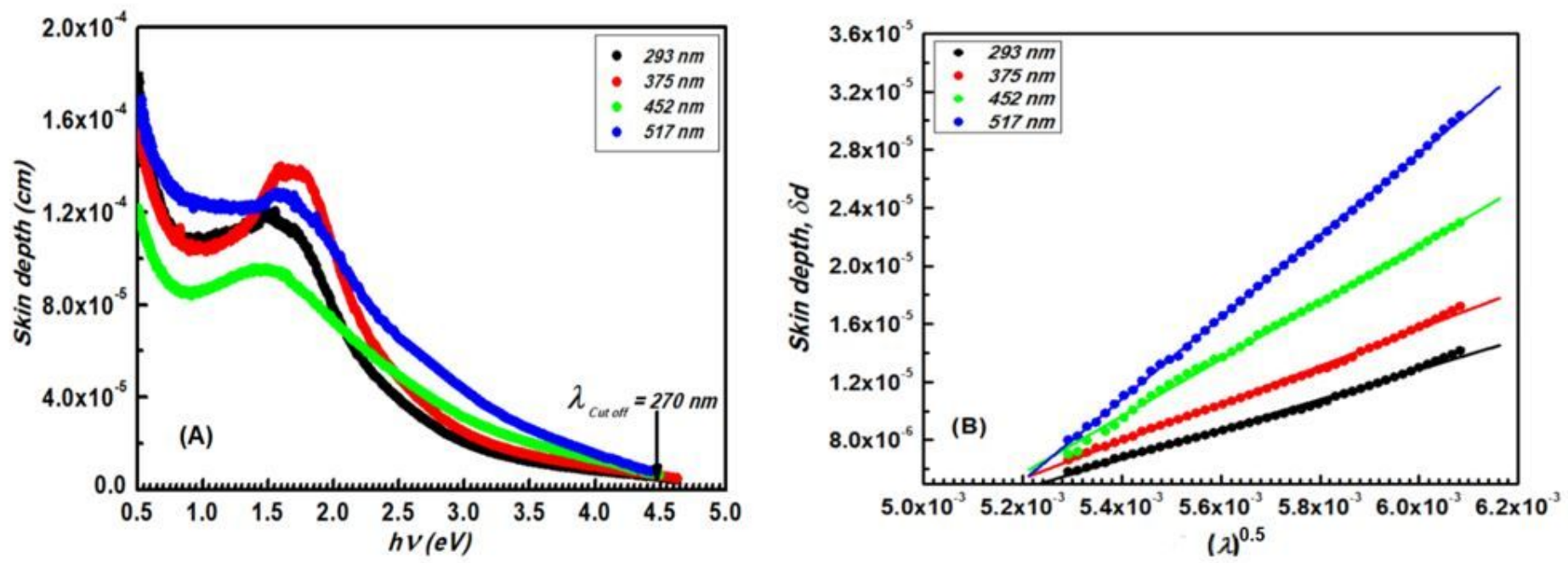

Figure 6

Variation of the skon depth as a function of (a) the photon energy and $\sqrt{ } \lambda$, for $\mathrm{ZnGa2S} 4$ films of different thicknesses. 

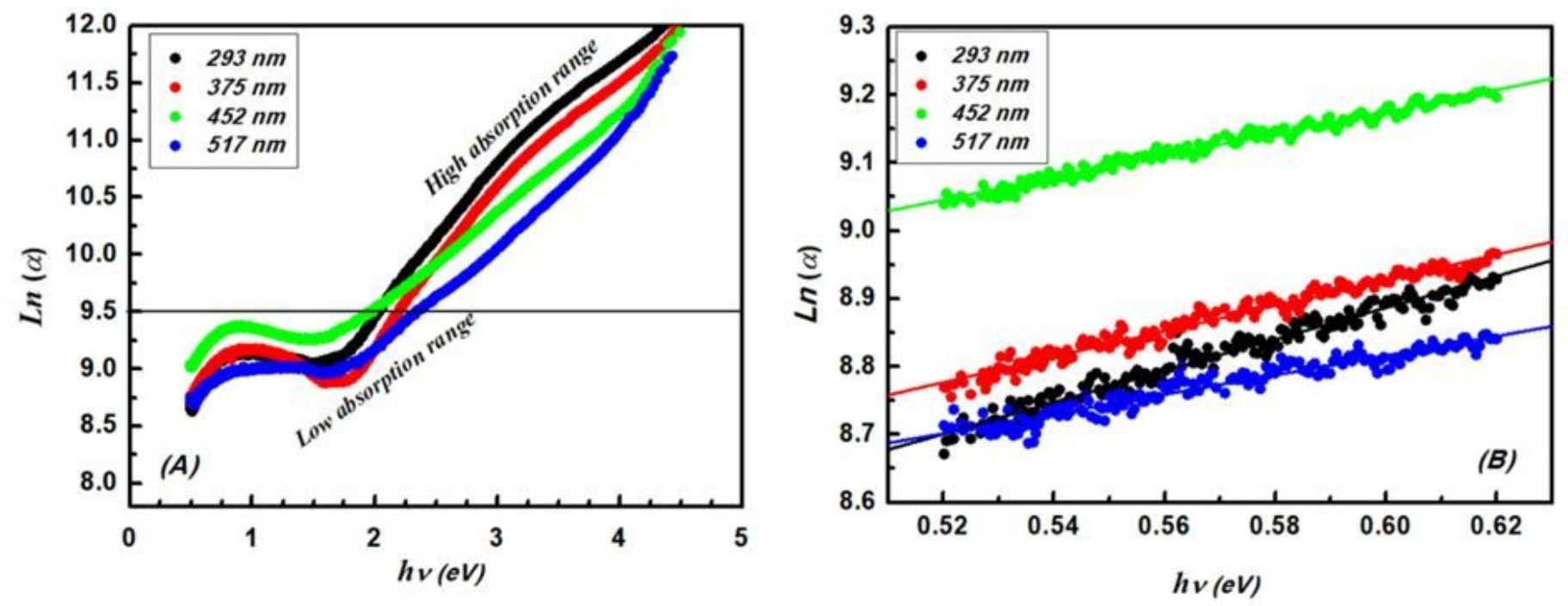

Figure 7

Plotting of In (a) versus (hu) of the polycrystalline ZnGa2S4 thin films. (A) shows the low and high absorption range (Urbach and Tauc regions, respectively) and (B) shows linear relationship. 

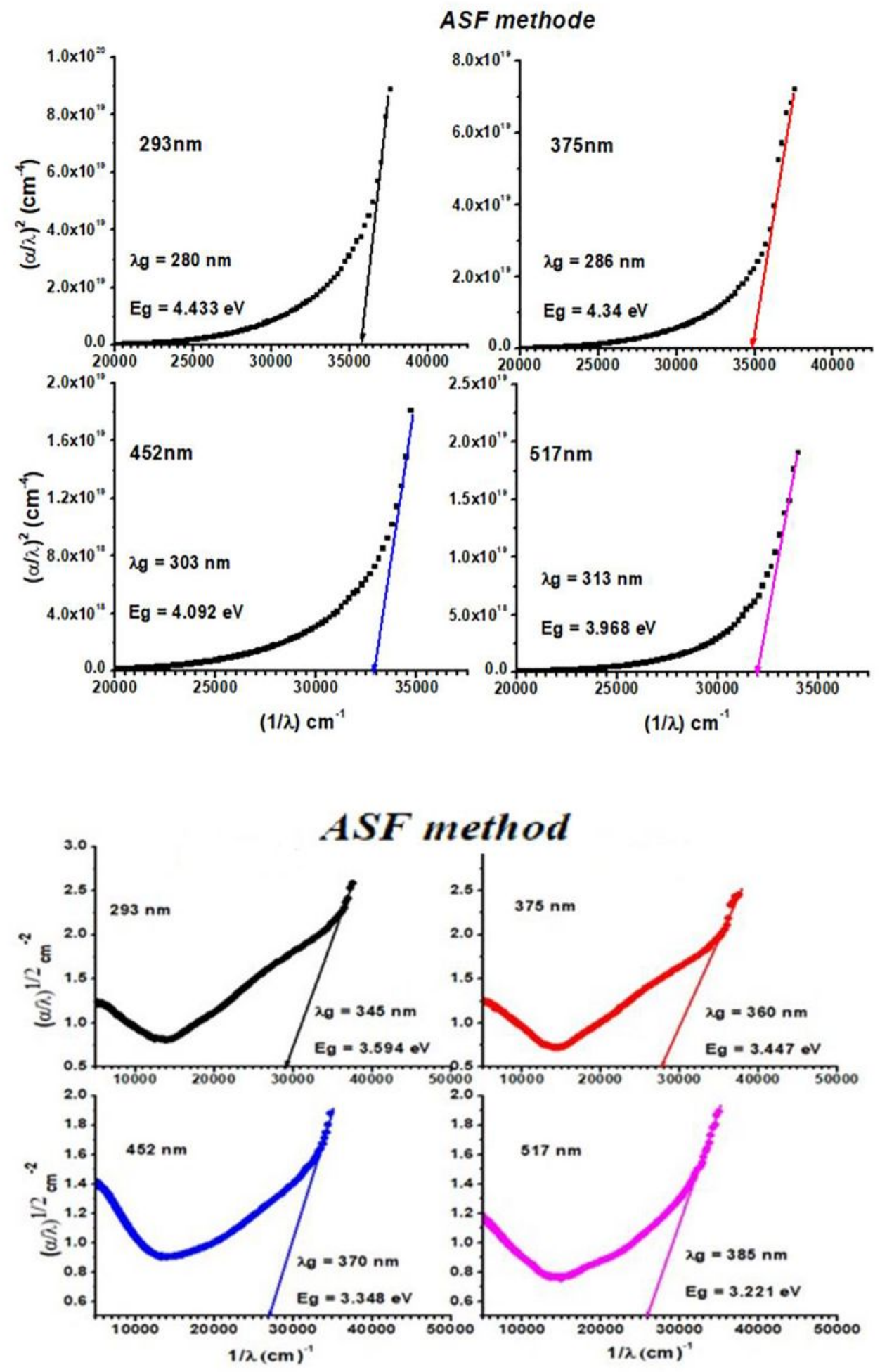

\section{Figure 8}

a.Plotting of $(\alpha / \lambda) 2$ versus $(1 / \lambda)$ for thin ZnGa2S4 films of different thicknesses to obtain the direct bandgap energy. $b$. Plots of $(a / \lambda) 1 / 2$ versus $(1 / \lambda)$ of thin $Z n G a 2 S 4$ films with different thicknesses to get their indirect band-gap energy values. 

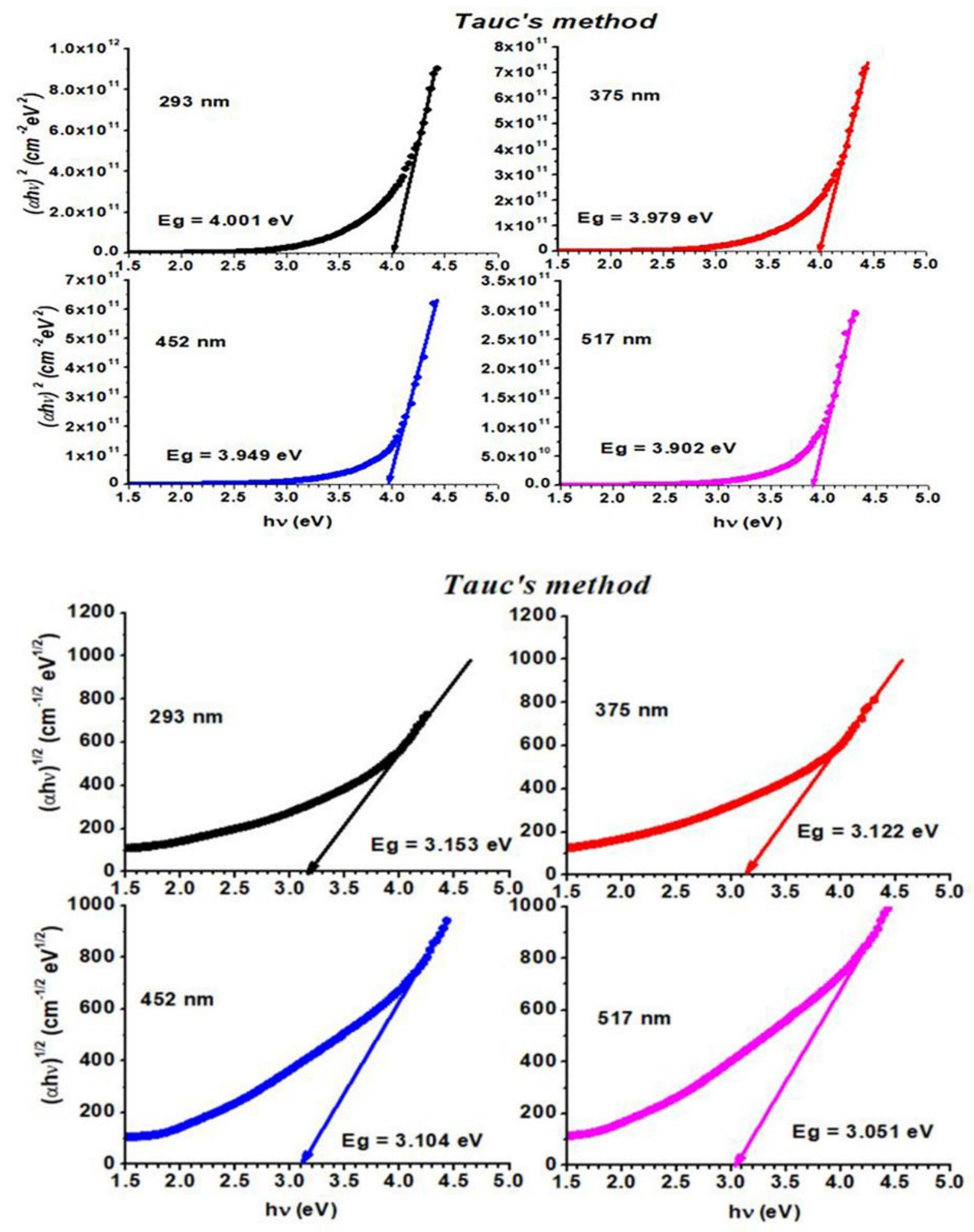

Figure 9

a. The graphical relationship between (ahv)2 and (hv) according to Tauc's plots for the ternary ZnGa2S4 thin film with different thicknesses. b. The graphical relationship between (ahv) $1 / 2$ and (hv) according to Tauc's method for the ternary ZnGa2S4 thin film with different thicknesses. 


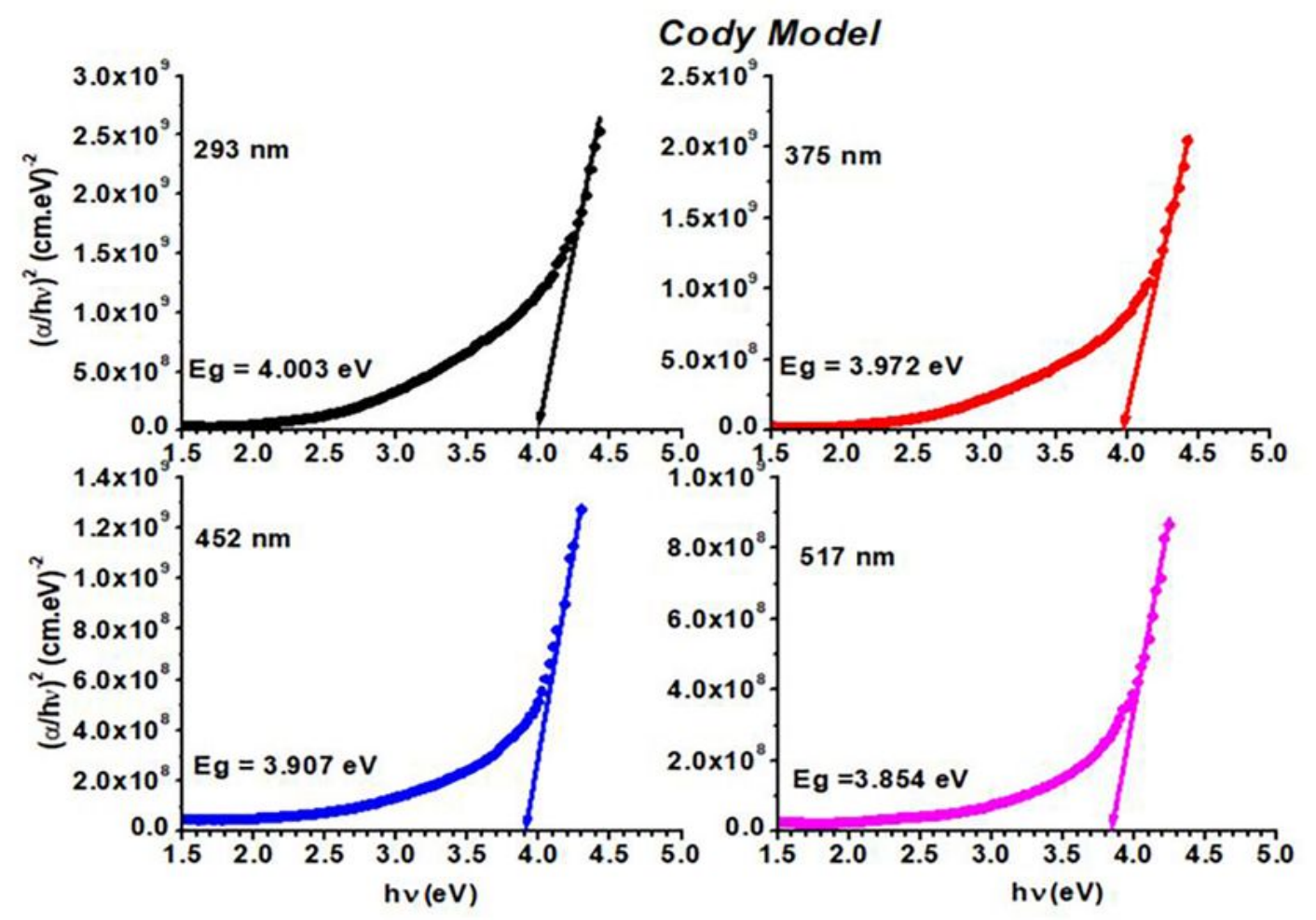

\section{Cody Model}
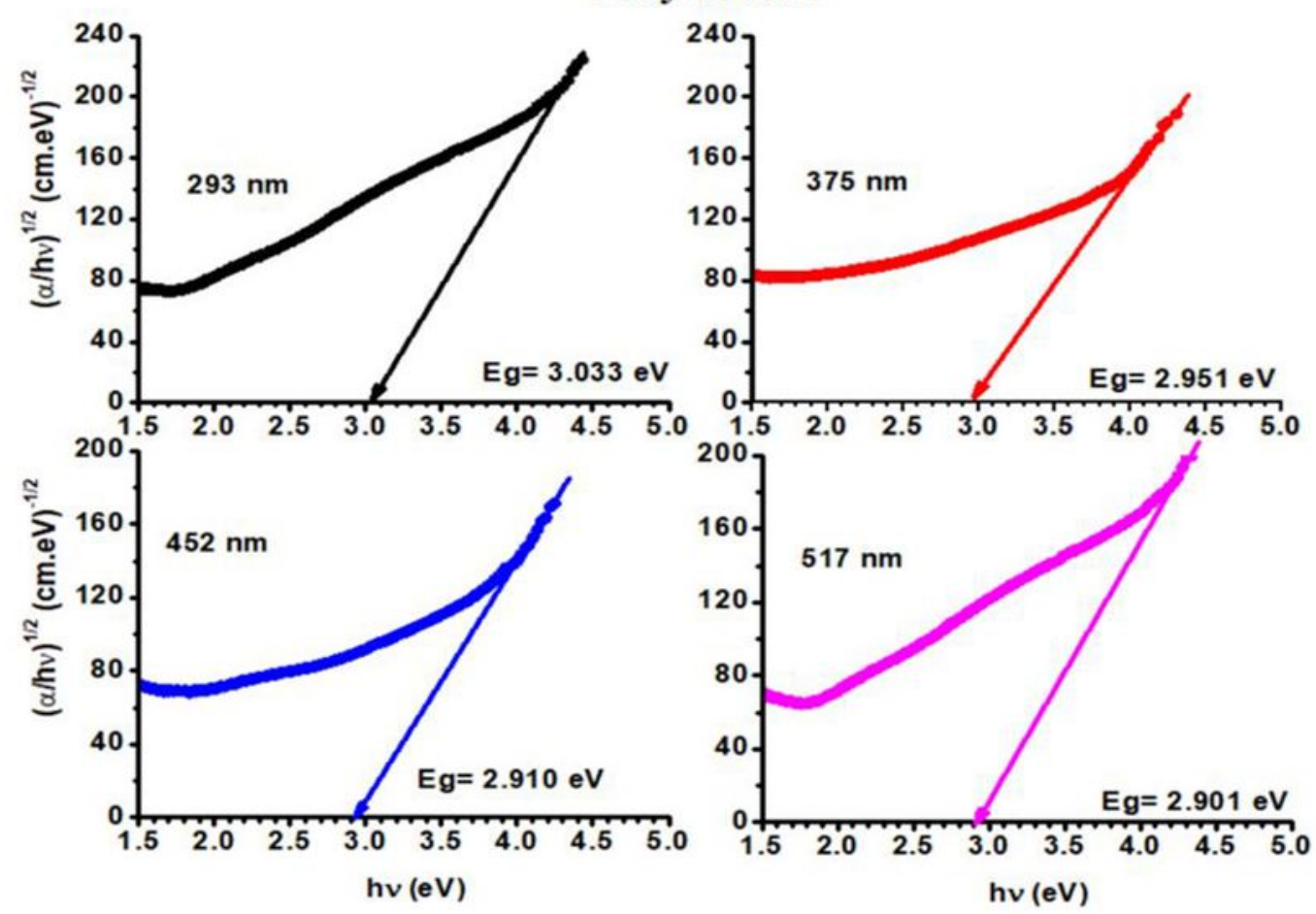

Figure 10

a. Plots of the graphical relationship between $(\mathrm{a} / \mathrm{hv}) 2$ versus (hv) according to Cody model for the ternary compound ZnGa2S4 thin film with different thicknesses. b. Plot the graphical relationship between (a/hv)1/2 versus hv according to Code model for the ternary compound ZnGa2S4 thin film with different thicknesses. 

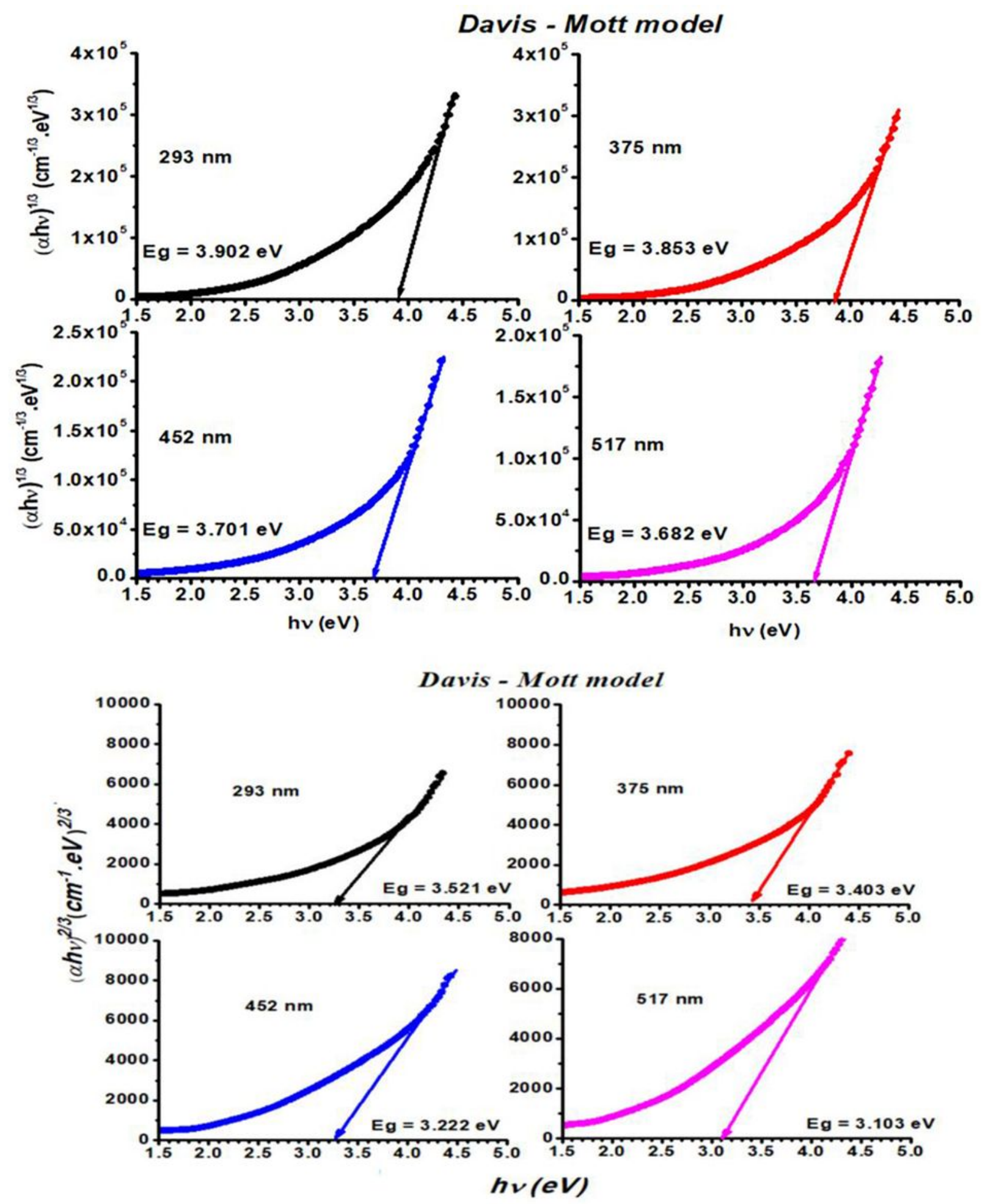

Figure 11

a. The graphical relationship between (ahv) $1 / 3$ and (hv), in accordance with the Davis-Mott model of the ternary ZnGa2S4 thin film. b. The graphical relationship between (ahv)2/3and (hv) in accordance with Davis-Mott model for the ternary ZnGa2S4 thin film. 


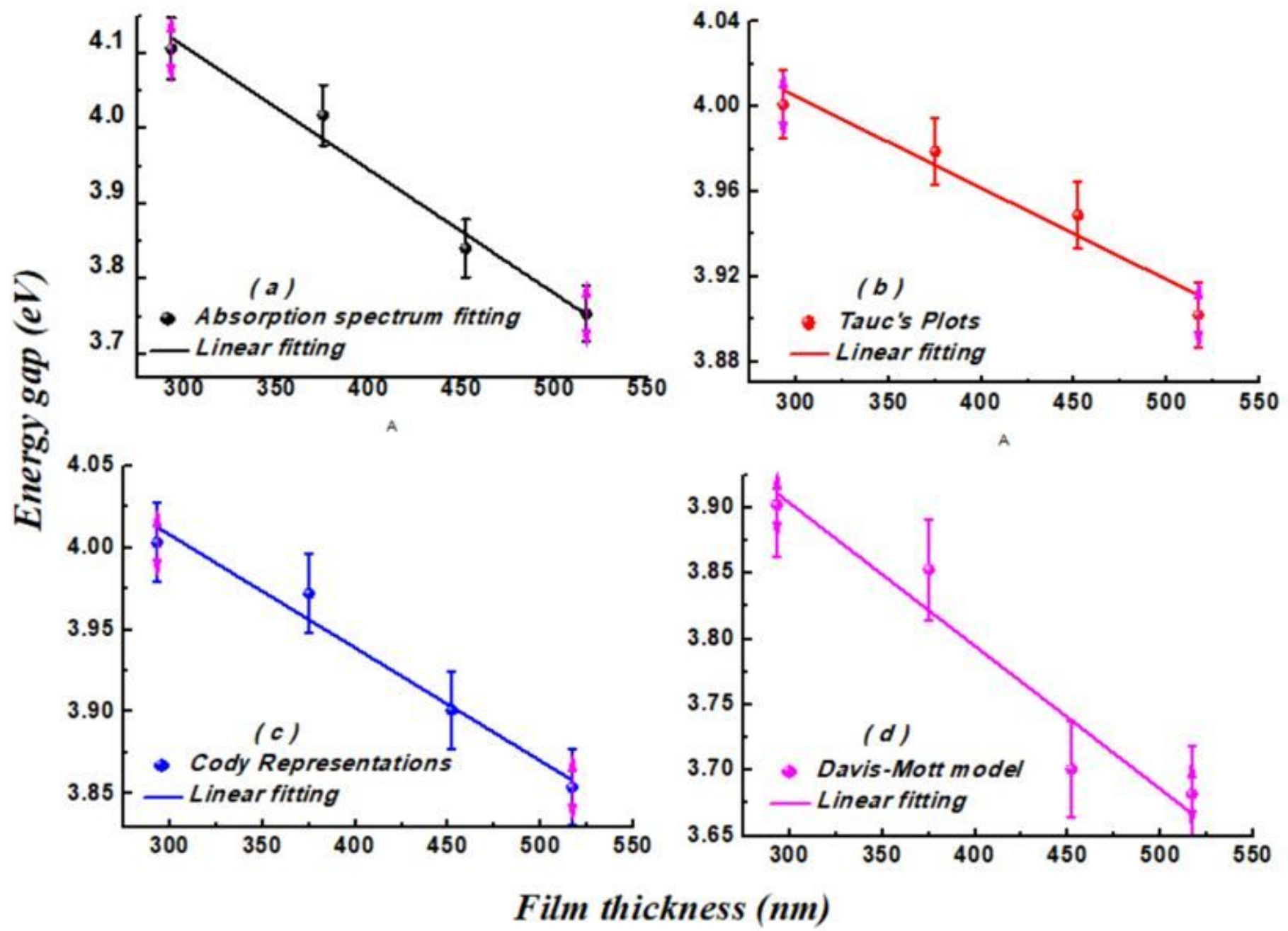

Figure 12

The dependence of the direct optical energy gap upon the film thickness as computed by different methods for the ternary ZnGa2S4 thin films. 